\title{
Belief and Plausibility Measures on Intuitionistic Fuzzy Sets with Construction of Belief-Plausibility TOPSIS
}

\author{
Miin-Shen Yang $\mathbb{D D}^{1}{ }^{2}$ Zahid Hussain, ${ }^{2}$ and Mehboob Ali ${ }^{1}$ \\ ${ }^{1}$ Department of Applied Mathematics, Chung Yuan Christian University, Chung-Li 32023, Taoyuan, Taiwan \\ ${ }^{2}$ Department of Mathematics, Karakoram International University, Gilgit-Baltistan, Pakistan \\ Correspondence should be addressed to Miin-Shen Yang; msyang@math.cycu.edu.tw
}

Received 8 April 2020; Accepted 20 July 2020; Published 12 August 2020

Academic Editor: Mojtaba Ahmadieh Khanesar

Copyright (C) 2020 Miin-Shen Yang et al. This is an open access article distributed under the Creative Commons Attribution License, which permits unrestricted use, distribution, and reproduction in any medium, provided the original work is properly cited.

\begin{abstract}
Belief and plausibility measures in Dempster-Shafer theory (DST) and fuzzy sets are known as different approaches for representing partial, uncertainty, and imprecise information. There are several generalizations of DST to fuzzy sets proposed in the literature. But, less generalization of DST to intuitionistic fuzzy sets (IFSs), that can somehow present imprecise information better than fuzzy sets, was proposed. In this paper, we first propose a simple and intuitive way to construct a generalization of DST to IFSs with degrees of belief and plausibility in terms of degrees of membership and nonmembership, respectively. We then give belief and plausibility measures on IFSs and construct belief-plausibility intervals (BPIs) of IFSs. Based on the constructed BPIs, we first use Hausdorff metric to define the distance between two BPIs and then establish similarity measures in the generalized context of DST to IFSs. By employing the techniques of ordered preference similarity to ideal solution (TOPSIS), the proposed belief and plausibility measures on IFSs in the framework of DST enable us to construct a belief-plausibility TOPSIS for solving multicriteria decision-making problems. Some examples are presented to manifest that the proposed method is reasonable, applicable, and well suited in the environment of IFSs in the framework of generalization of DST.
\end{abstract}

\section{Introduction}

In real world, there exists much uncertainty that is random, fuzzy, vague, imprecise, and ambiguous. Traditionally, probability has been used to model uncertainty under randomness. Belief and plausibility measures based on Dempster-Shafer theory (DST) $[1,2]$ are emerged as another way of measuring uncertainty in which they have been widely studied and applied in many areas $[3,4]$. The theory of evidence, interpreted by Shafer [2], intended to generalize probability theory. On the contrary, two-value logic based on set theory is somehow difficult for handling complex systems, and so Zadeh [5] proposed fuzzy sets (FSs) as an extension of ordinary sets. Since then, fuzziness has been widely employed to handle a type of uncertainty that is different from probability/randomness. FSs are based on membership values between 0 and 1 . However, in some reallife settings, it may not be always true that nonmembership degree is equal to one minus membership degree. Therefore, to get more purposeful reliability and applicability, Atanassov $[6,7]$ generalized FSs to intuitionistic fuzzy sets (IFSs) which include both membership degree and nonmembership degree with a degree of nondeterminacy. That is, an IFS $A$ in $X$ is a pair grade, denoted by $(\mu, \nu)$, with the condition $0 \leq \mu(x)+\nu(x) \leq 1, \forall x \in X$, and a degree of nondeterminacy $\pi(x)=1-\mu(x)-\nu(x)$. IFSs are an extension of FSs in which it can be utilized to model those uncertain and vague situations with more available information than FSs. Characterization of IFSs is important as it has many applications in different areas, such as a graphical method for ranking IFS values using entropy [8], hybrid aggregation operators for triangular IFSs [9], and IFS graphs with applications [10].

The generalization of DST to fuzzy sets was first given by Zadeh [11]. Subsequently, various generalizations of DST to fuzzy sets were proposed [12-15]. But, less generalization of 
DST to IFSs was proposed in the literature. Hwang and Yang [16] proposed a generalization of belief and plausibility functions to IFSs based on fuzzy integral where the generalization is able to catch more information about the change in intuitionistic fuzzy focal elements on DST. In $[17,18]$, they mentioned that there is a strong link between the theory of IFSs and the evidence theory of DST that makes it possible to aggregate local criteria without limitation. They also suggested an approach as the solution of these problems based on the interpretation of IFSs in the framework of DST. However, in $[17,18]$, they did not give consideration on a generalization of belief and plausibility measures on IFSs.

In this paper, we propose belief (Bel) and plausibility (Pl) measures on IFSs in the framework of DST. We first give a simple and intuitive way to construct the degrees of belief and plausibility in terms of degrees of membership and nonmembership in an IFS, respectively. We then propose belief and plausibility measures on IFSs and construct beliefplausibility intervals (BPIs) of IFSs. Distance and similarity measures are important tools for determining the degree of difference and degree of similarity between two objects. Various distance and similarity measures between fuzzy sets/ IFSs had been widely studied and applied in the literature [19-22]. In this paper, we also create new distance and similarity measures between BPIs of IFSs by using Hausdorff metric. These similarity measures between BPIs of IFSs are then applied in multicriteria decision-making by constructing a belief-plausibility TOPSIS.

The remainder of the paper is organized as follows. In Section 2, we review some basic concepts of DST and also demonstrate briefly the interpretations of IFSs in the framework of DST. In Section 3, we exhibit these proposed Bel and Pl measures on IFSs in the context of DST. We also give more properties of these proposed Bel and $\mathrm{Pl}$ measures on IFSs. In Section 4, we create BPIs of IFSs based on the proposed Bel and $\mathrm{Pl}$ measures on IFSs. We then use Hausdorff metric to give new distance and similarity measures between BPIs of IFSs. Some examples are used to demonstrate that the proposed methods are reasonable and well suited in the environment of IFSs in the context of DST. In Section 5, we construct a belief-plausibility TOPSIS based on the proposed Bel and Pl measures on IFSs for solving multicriteria decision-making (MCDM) problems, which will lead us to rank and then select the best alternative among many alternatives. Finally, conclusions are stated in Section 6.

\section{Preliminaries}

In this section, we first give a brief review of DST and then review some basic definitions of IFSs with previously defined belief and plausible measures on IFSs in the literature.

2.1. Dempster-Shafer Theory. The lower and upper probabilities were initially proposed by Dempster [1] using a multivalued mapping. One decade later, Shafer [2] developed belief and plausibility measures on ordinary subsets based on Dempster's lower and upper probabilities.
Consider a triplet $(\Omega, M, P)$ as a probability space and a multivalued mapping, denoted by $\Psi$, from $\Omega$ to $\Theta$ which assigns a subset $\Psi(\omega) \subset \Theta$ to every $\omega \in \Omega$. That is, $\Psi$ is a setvalued function from $\Omega$ to the power set $2^{\Theta}$ of $\Theta$. For any subset $S$ of $\Theta$, we have $S_{*}=\{\omega \in \Omega: \Psi(\omega) \subset S, \Psi(\omega) \neq \phi\}$ and $S^{*}=\{\omega \in \Omega: \Psi(\omega) \cap S \neq \phi\}$. In particular, $\Theta_{*}=\Theta^{*}=\Omega$. Let $\mathrm{K}$ be the class of subsets $S$ of $\Theta$ so that $S_{*}$ and $S^{*}$ belong to $M$. Then, the lower probability $P_{*}$ and upper probability $P^{*}$ of $S$ in $\mathrm{K}$ are defined as

$$
\begin{aligned}
& P_{*}(S)=\frac{P\left(S_{*}\right)}{P\left(\Theta^{*}\right)}, \\
& P^{*}(S)=\frac{P\left(S^{*}\right)}{P\left(\Theta^{*}\right)},
\end{aligned}
$$

where $P_{*}(S)$ and $P^{*}(S)$ can only be defined if $P\left(\Theta^{*}\right) \neq 0$. It can be shown that $P_{*}(S)=1-P^{*}\left(S^{c}\right), P_{*}(S)+P_{*}\left(S^{c}\right) \leq 1$, $P^{*}(S)+P^{*}\left(S^{c}\right) \geq 1$, and $P_{*}(S) \leq P^{*}(S)$. It is worthy to mention that if $\Psi$ is a single valued function, then $\Psi$ becomes a random variable with $P_{*}(S)=P^{*}(S)$. On the contrary, if $\Psi$ is a multivalued mapping, then an outcome $\omega$ may be mapped to more than one value.

Furthermore, suppose that $\Theta$ is a finite set. A set function is defined by Shafer [2] as a mapping from the power set of the discernment space into unit interval, i.e., $m: 2^{\Theta} \longrightarrow[0,1]$, with the conditions: (i) $m(\phi)=0$ and (ii) $\sum_{S_{i} \in 2^{\Theta}} m\left(S_{i}\right)=1$. The function $m$, also known as basic probability assignment (BPA), assigns an identical weight to every subset of $S \subseteq \Theta$ from the available evidence. An element $S$ in the power set $2^{\Theta}$ with $m(S) \neq 0$ is called a focal element. A belief (Bel) measure is a function Bel: $2^{\Theta} \longrightarrow[0,1]$, and a plausibility $(\mathrm{Pl})$ measure is a function $\mathrm{Pl}: 2^{\Theta} \longrightarrow[0,1]$ in which they are defined as any element $S$ in $2^{\Theta}, \operatorname{Bel}(S)=$ $\sum_{T \subset S} m(T)=P_{*}(S)$, and $\operatorname{Pl}(S)=\sum_{T \cap S \neq \phi} m(T)=P^{*}(S)$, where $\operatorname{Bel}(S)=1-\operatorname{Pl}\left(S^{c}\right)$ and $\operatorname{Pl}(S)=1-\operatorname{Bel}\left(S^{c}\right)$.

2.2. Intuitionistic Fuzzy Sets. We next give a brief review of IFSs with these belief and plausible functions on IFSs proposed in the literature.

Definition 1 (Atanassov [6, 7]). An intuitionistic fuzzy set (IFS) $\widetilde{S}$ in $X$ is defined by the form $\widetilde{S}=\left\{\left(x, \mu_{S}(x), v_{S}(x)\right) \mid x \in X\right\}$ with the condition $0 \leq \mu_{S}(x)+\nu_{S}(x) \leq 1$, where the function $\mu_{S}(x): X \longrightarrow[0,1]$ denotes the degree of membership of $x \in \widetilde{S}$, and $\nu_{S}(x): X \longrightarrow[0,1]$ denotes the degree of nonmembership of $x \in \widetilde{S}$. For any $x \in X, \pi_{\widetilde{S}}(x)=1-\left(\mu_{\tilde{S}}(x)+\right.$ $\left.\nu_{S}(x)\right)$ is called the intuitionistic fuzzy index of the element $x$ to the IFS $\widetilde{S}$ for representing the degree of uncertainty.

Definition 2 (Atanassov [6, 7]). If $\widetilde{S}$ and $\widetilde{T}$ are two IFSs of the set $X$, then the following holds:

(i) $\widetilde{S} \subseteq \widetilde{T}$ if and only if $\forall x \in X, \mu_{S}(x) \leq \mu_{T}(x)$ and $v_{S}(x) \geq v_{T}(x)$

(ii) $\widetilde{S}=\widetilde{T}$ if and only if $\forall x \in X, \mu_{S}(x)=\mu_{\tau}(x)$ and $v_{S}(x)=v_{T}(x)$ 
(iii) $\widetilde{S} \cup \widetilde{T}=\left\{\max \left(\mu_{S}(x), \mu_{\widetilde{T}}(x)\right), \min \left(\nu_{S}(x), \nu_{\widetilde{T}}(x)\right)\right\}$, $\forall x \in X$

(iv) $\widetilde{S} \cap \widetilde{T}=\left\{\min \left(\mu_{S}(x), \mu_{\widetilde{T}}(x)\right), \max \left(\nu_{S}(x), \nu_{T}(x)\right)\right\}$, $\forall x \in X$

Dymova and Sevastjanov $[17,18]$ used DST as an interpretation of IFS. In [17, 18], the following three hypotheses are implicitly used to make the connection between DST and IFSs: (i) $x_{j} \in \widetilde{S}: m($ Yes $)=\mu_{\widetilde{S}}\left(x_{j}\right)$, (ii) $x_{j} \notin \widetilde{S}: m(\mathrm{No})=v_{S}\left(x_{j}\right)$, and (iii) $m\left(\right.$ Yes, No) $=\pi_{\widetilde{S}}\left(x_{j}\right)$ represents that both $x_{j} \in \widetilde{S}$ and $x_{j} \notin \widetilde{S}$ hypotheses cannot be rejected. Consider the fact $\mu_{S}(x)+\nu_{s}(x)+\pi_{s}(x)=1$, and so $\operatorname{Bet}_{S}\left(x_{j}\right)=m($ Yes $)=\mu_{S}\left(x_{j}\right)$ and $\operatorname{Pr}_{S}\left(x_{j}\right)=m($ Yes $)+$ $m($ Yes, No $)=\mu_{S}\left(x_{j}\right)+\pi_{S}\left(x_{j}\right)=1-v_{S}\left(x_{j}\right)$. Based on these notions, belief intervals can be constructed in Dymova and Sevastjanov $[17,18]$. Some Bel and Pl functions on IFSs were proposed by Hwang and Yang [16] using the concept of Sugeno integral defined by Ban [23]. However, the generalizations of belief and plausibility on IFSs defined by Hwang and Yang [16] are very complicated, and so they are hard to be followed and also difficult to be applied in MCDM. In next section, we propose a simple and intuitive approach for defining belief and plausibility measures on IFSs in the framework of DST.

\section{New Belief and Plausibility Measures on Intuitionistic Fuzzy Sets}

In this section, we first give the interpretation of IFSs in the framework of DST. We then propose new belief (Bel) and plausible ( $\mathrm{Pl})$ measures on IFSs with the construction of belief-plausible intervals (BPIs). In the framework of DST, a Bel measure on a set $\widetilde{S}$ with its complement $\widetilde{S}^{c}$ has $\operatorname{Bel}(\widetilde{S})+\operatorname{Bel}\left(\widetilde{S}^{c}\right) \leq 1$. Therefore, DST is different from probability. In the context of DST, the degree of belief committed to a proposition and its complement may not be one but has a degree of ignorance. In the case of total ignorance, it is even with $\operatorname{Bel}(\widetilde{S})=\operatorname{Bel}\left(\widetilde{S}^{c}\right)=0$. For this reason, the belief committed to a proposition $\widetilde{S}$ may not be fully described by the belief function $\operatorname{Bel}(\widetilde{S})$. It is necessary to assign a doubt function $\operatorname{Dou}(\widetilde{S})$ committed to the proposition $\widetilde{S}$, i.e., the belief committed to its complement $\widetilde{S}^{c}$. That is, $\operatorname{Dou}(\widetilde{S})=\operatorname{Bel}\left(\widetilde{S}^{c}\right)$ is used to achieve a full description of the belief committed to $\widetilde{S}$. Some discussion about doubt functions was also given by Salicone [24, 25].

It is observed that DST and IFSs are intuitively interlinked to each other and have some relations between them. Since the degree of membership $\mu_{\varsigma}(x)$ for any $x$ in an IFS $\widetilde{S}$ is analogous to the degree of belief $\operatorname{Bel}(\{x\})$ in DST for the singleton $x$, it provides an insight to express the degree of belief in terms of the degree of membership for any $x$ in $\widetilde{S}$. Thus, we may assign $\operatorname{Ber}_{S}(x)=\mu_{S}(x)$, which actually reflects the connection between the degrees of membership and belief. In this sense, $\operatorname{Bel}_{\widetilde{S}}(x)$ is regarded as the degree of belief, credibility, or evidence of an element $x$ in $\widetilde{S}$, and so it can be also denoted by $\mu_{\tilde{S}}(x)$. We can also assign the degree of doubt about the occurrence of an element $x$ in $\widetilde{S}$ with $\operatorname{Bel}_{s}(x)$. Since, both degrees of membership and nonmembership are represented by $\langle\mu(x), \nu(x)\rangle$ in IFSs, we can write the complement of an IFS $\widetilde{S}$ in terms of degree of doubt for each element $x$ in $\widetilde{S}$ with $\operatorname{Bel}_{s}(x)=v_{S}(x)$. In fact, both $\operatorname{Bel}_{\tilde{S}}(x)$ and $\operatorname{Bel}_{S}^{-c}(x)$ can be acted as personal judgement. In this sense, a complete description about an IFS $\widetilde{S}$ should be better given both belief function $\operatorname{Bel}_{S}(x)$ and doubt function $\operatorname{Dour}_{\widetilde{S}}(x)=\operatorname{Bel}_{\varsigma}(x)$. On the contrary, the plausibility function $\operatorname{Pr}_{S}(x)$ can be expressed in terms of the doubt function as $\mathrm{Pl}_{\hat{S}}(x)=1-\operatorname{Bel}_{\hat{S}} \quad(x)=1-\operatorname{Dou}_{\tilde{S}}(x)=$ $1-v_{S}(x)=\mu_{S}(x)+\pi_{\widetilde{S}}(x)$. Thus, the plausibility function $\mathrm{Pr}_{\tilde{S}}(x)$ associated with the IFS $\widetilde{S}$ indicates the extent to which one fails to doubt $\widetilde{S}$ or, in other words, the extent to which one finds that $\widetilde{S}$ is plausible. Since the ordered triple $\left(\mu_{\mathcal{S}}(x), \gamma_{\mathcal{S}}(x), \pi_{\tilde{S}}(x)\right)$ of an IFS $\widetilde{S}$ has the property $\mu_{S}(x)+v_{S}(x)+\pi_{S}(x)=1$, it may represent the basic probability assignment (BPA) in the context of DST. Therefore, we give the following definitions and propose these belief and plausibility measures on intuitionistic fuzzy sets.

Definition 3. Let $X$ be a finite universe of discourses and let $\widetilde{S}$ be an IFS of $X$. A belief function of an element $x$ in $\widetilde{S}$, denoted by $\operatorname{Bel}_{\mathcal{S}}(x)$, is defined as a real-valued function with

$$
\operatorname{Bet}_{S}(x)=\mu_{S}(x), \quad \forall x \in X \text {. }
$$

Definition 4. Let $X$ be a finite universe of discourses, and let $\widetilde{S}$ be an IFS of $X$. A plausibility function of an element $x$ in $\widetilde{S}$, denoted by $\mathrm{Pl}_{S}(x)$, is defined as a real-valued function with

$$
\mathrm{Pl}_{S}(x)=1-v_{S}(x), \quad \forall x \in X .
$$

Definition 5. Let $X=\left\{x_{1}, x_{2}, \ldots, x_{n}\right\}$ be a fine universe of discourses and let $\widetilde{S}$ be an IFS on $X$. A belief measure Bel on $\widetilde{S}$ under weights $w_{i}$ with $\sum_{i=1}^{n} w_{i}=1$ is defined as

$$
\operatorname{Bel}(\widetilde{S})=\sum_{i=1}^{n} w_{i} \operatorname{Bet}_{S}\left(x_{i}\right) \text {. }
$$

Definition 6. Let $X=\left\{x_{1}, x_{2}, \ldots, x_{n}\right\}$ be a universe of discourse, and let $\widetilde{S}$ be an IFS on $X$. A plausibility measure $\mathrm{Pl}$ on $\widetilde{S}$ under weights $w_{i}$ with $\sum_{i=1}^{n} w_{i}=1$ is defined as

$$
\operatorname{Pl}(\widetilde{S})=\sum_{i=1}^{n} w_{i} \operatorname{Pl}_{S}\left(x_{i}\right) \text {. }
$$

In general, the weights $w_{i}$ are assigned to be $(1 / n)$ in Definitions 5 and 6 . We now discuss some properties of the proposed Bel and $\mathrm{Pl}$ measures on IFSs.

Theorem 1. Bel and Pl measures on IFSs in equations (4) and (5) obey the following properties:

(1) $0 \leq \operatorname{Bel}(\widetilde{S}) \leq P l(\widetilde{S}) \leq 1$

(2) If $\widetilde{S}_{1} \subseteq \widetilde{S}_{2}$ then $\operatorname{Bel}\left(\widetilde{S}_{1}\right) \leq \operatorname{Bel}\left(\widetilde{S}_{2}\right)$ and $\operatorname{Pl}\left(\widetilde{S}_{1}\right) \leq \operatorname{Pl}\left(\widetilde{S}_{2}\right)$

(3) $\operatorname{Bel}(\widetilde{S})=1-\operatorname{Pl}\left(\widetilde{S}^{c}\right)$ and $\operatorname{Pl}(\widetilde{S})=1-\operatorname{Bel}\left(\widetilde{S}^{c}\right)$

(4) $\operatorname{Bel}(\widetilde{S})+\operatorname{Bel}\left(\widetilde{S}^{c}\right) \leq 1$ and $P l(\widetilde{S})+P l\left(\widetilde{S}^{c}\right) \geq 1$ 
Proof

(1) Let $\widetilde{S}$ be an IFS. We have $0 \leq \mu_{S}(x) \leq \mu_{S}(x)+\pi_{S}(x) \leq 1, \quad \forall x \in X, \quad \pi_{\widetilde{S}}\left(x_{i}\right) \geq 0$. This implies $0 \leq \mu_{S}(x) \leq 1-v_{S}(x) \leq 1$, and then $0 \leq \operatorname{Bel}_{S}(x) \leq \operatorname{Pl}_{\mathcal{S}}(x) \leq 1$. Thus, we have $0 \leq \sum_{i=1}^{n^{S}} w_{i} \operatorname{Ber}_{S}\left(x_{i}\right) \leq \sum_{i=1}^{n} w_{i} \operatorname{Pl}_{S}\left(x_{i}\right) \leq \sum_{i=1}^{n} w_{i}=1$, and then, $0 \leq \operatorname{Bel}(\widetilde{S}) \leq \operatorname{Pl}(\widetilde{S}) \leq 1$.

(2) Let $\widetilde{S}_{1}$ and $\widetilde{S}_{2}$ be any two IFSs with $\widetilde{S}_{1} \subseteq \widetilde{S}_{2}$. We have $\mu_{S}(x) \leq \mu_{S}(x), \forall x \in X$. This implies Bel $_{S_{1}}(x) \leq \operatorname{Bel}_{S_{2}}(x), \quad \forall x \in X, \quad$ and then $\sum_{i=1}^{n} w_{i} \operatorname{Bel}_{S_{1}}\left(x_{i}\right) \leq \sum_{i=1}^{n} w_{i} \operatorname{Bel}_{S_{2}}\left(x_{i}\right)$. We obtain that $\operatorname{Bel}\left(\widetilde{S}_{1}\right) \leq \operatorname{Bel}\left(\widetilde{S}_{2}\right)$. Similarly, we can prove that, if $\widetilde{S}_{1} \subseteq \widetilde{S}_{2}$, then $\operatorname{Pl}\left(\widetilde{S}_{1}\right) \leq \operatorname{Pl}\left(\widetilde{S}_{2}\right)$.

(3) Since $\quad \operatorname{Bel}(\widetilde{S})=\sum_{i=1}^{n} w_{i} \operatorname{Bet}_{S} \quad\left(x_{i}\right)=$ $\sum_{i=1}^{n} w_{i} \mu_{S}\left(x_{i}\right)=1-\sum_{i=1}^{n} \quad w_{i}+\sum_{i=1}^{n} w_{i} \mu_{S}\left(x_{i}\right)=$ $1-\sum_{i=1}^{n} w_{i}\left(1-\mu_{c}\left(x_{i}\right)\right)=1-\operatorname{Pl}\left(\widetilde{S}^{c}\right)$, we have that $\operatorname{Bel}(\widetilde{S})=1-\operatorname{Pl}\left(\widetilde{S}^{\varepsilon}\right)$. Similarly, we have that $\operatorname{Pl}(\widetilde{S})=1-\operatorname{Bel}\left(\widetilde{S}^{c}\right)$.

(4) Since $\quad 0 \leq \operatorname{Bel}(\widetilde{S}) \leq 1, \quad 0 \leq \operatorname{Pl}(\widetilde{S}) \leq 1$, with $0 \leq \operatorname{Bel}(\widetilde{S}) \leq \operatorname{Pl}(\widetilde{S}) \leq 1$, we have $\operatorname{Bel}(\widetilde{S}) \leq 1-\operatorname{Bel}\left(\widetilde{S}^{c}\right)$. Hence, $\operatorname{Bel}(\widetilde{S})+\operatorname{Bel}\left(\widetilde{S}^{c}\right) \leq 1$. Similarly, we can show that $\operatorname{Pl}(\widetilde{S})+\operatorname{Pl}\left(\widetilde{S}^{c}\right) \geq 1$.
Example 1. Let the universe of discourse be $X=\left\{x_{1}, x_{2}, x_{3}, x_{4}, x_{5}\right\}$. Let $\widetilde{S}$ be an IFS in $X$ with $\widetilde{S}=\left\{\left(x_{1}, 0.05,0.75\right),\left(x_{2}, 0.35,0.55\right), \quad\left(x_{3}, 0.55,0.40\right)\right.$, $\left.\left(x_{4}, 0.65,0.05\right),\left(x_{5}, 1.0,0.0\right)\right\}$. The degrees of belief and plausibility for elements $x_{i}$ in $\widetilde{S}$ are found as follows: $\operatorname{Bet}_{S}\left(x_{1}\right)=0.05, \quad \operatorname{Bel}_{S}\left(x_{2}\right)=0.35, \quad \operatorname{Bet}_{S}\left(x_{3}\right)=0.55$, $\operatorname{Bet}_{S}^{S}\left(x_{4}\right)=0.65$, and Bel- $\left(x_{5}\right)=1.0$. Similarly, $\operatorname{Pr}_{S}\left(x_{1}\right)=$ $0.25, \mathrm{Pl}_{S}\left(x_{2}\right)=0.45, \operatorname{Pl}_{S}^{S}\left(x_{3}\right)=0.60, \operatorname{Pl}_{S}\left(x_{4}\right)=0.95$, and $\mathrm{Pl}_{\vec{S}}\left(x_{5}\right) \stackrel{S}{=} 1.0$. Thus, the belief measure Bel on $\widetilde{S}$ under the weights $w_{1}=0.1, w_{2}=0.325, w_{3}=0.175, w_{4}=0.15$, and $w_{5}=0.25$ using Definition 5 is computed with $\operatorname{Bel}(\widetilde{S})=$ $\sum_{i=1}^{5} w_{i} \operatorname{Bel}_{S}\left(x_{i}\right)=0.563$. Similarly, we can find the plausibility measure $\mathrm{Pl}$ using Definition 6 with $\mathrm{Pl}(\widetilde{S})=$ $\sum_{i=1}^{5} w_{i} \mathrm{Pl}_{S}\left(x_{i}\right)=0.669$.

However, the proposed Bel and Pl measures on IFSs are entirely relied on memberships and nonmemberships. Therefore, in the next example, we observe the response of the proposed Bel and $\mathrm{Pl}$ measures due to change in memberships and nonmemberships of IFSs.

Example 2. Let the universe of discourses be $X=\left\{x_{1}, x_{2}, x_{3}, x_{4}, x_{5}\right\}$. Let $\widetilde{S}, \widetilde{T}_{1}, \widetilde{T}_{2}$, and $\widetilde{T}_{3}$ be IFSs with

$$
\begin{aligned}
\widetilde{S} & =\left\{\left(x_{1}, 0.25,0.55\right),\left(x_{2}, 0.45,0.35\right),\left(x_{3}, 0.55,0.25\right),\left(x_{4}, 0.7,0.15\right),\left(x_{5}, 1.0,0.0\right)\right\}, \\
\widetilde{T}_{1} & =\left\{\left(x_{1}, 0.25,0.55\right),\left(x_{2}, 0.45,0.35\right),\left(x_{3}, 0.55,0.25\right),\left(x_{4}, 0.85,0.05\right),\left(x_{5}, 1.0,0.0\right)\right\}, \\
\widetilde{T}_{2} & =\left\{\left(x_{1}, 0.25,0.55\right),\left(x_{2}, 0.45,0.35\right),\left(x_{3}, 0.55,0.25\right),\left(x_{4}, 0.65,0.25\right),\left(x_{5}, 1.0,0.0\right)\right\}, \\
\widetilde{T}_{3} & =\left\{\left(x_{1}, 0.25,0.55\right),\left(x_{2}, 0.45,0.35\right),\left(x_{3}, 0.55,0.25\right),\left(x_{4}, 0.95,0.0\right),\left(x_{5}, 1.0,0.0\right)\right\} .
\end{aligned}
$$

Since the degrees of belief and plausibility for elements $x_{i}$ in $\widetilde{S}$ are entirely relied on memberships $\mu(x)$ and nonmemberships $\nu(x)$, we can observe the response of the proposed belief and plausibility measures by taking three different IFSs $\widetilde{T}_{1}, \widetilde{T}_{2}$, and $\widetilde{T}_{3}$ with respect to the IFS $\widetilde{S}$ based on some variation in their membership and nonmembership values. It is seen that the IFSs $\widetilde{S}$ and $\widetilde{T}_{1}$ are with $\mu_{S}\left(x_{4}\right)<\mu_{T_{1}}\left(x_{4}\right)$ and $v_{S}\left(x_{4}\right)>v_{T_{1}}\left(x_{4}\right)$. By considering such type of variations in memberships and nonmemberships, we can easily observe the responses of the proposed belief and plausibility measures of equations (4) and (5) on the IFSs $\widetilde{S}$ and $\widetilde{T}_{1}$. Similarly, to notice the response of belief and plausibility measures on the IFSs $\widetilde{T}_{2}$ and $\widetilde{T}_{3}$ with respect to the IFS $\widetilde{S}$, we consider the following variations in membership and nonmembership values of the IFSs $\widetilde{S}$ and $\widetilde{T}_{2}$, respectively, as $\mu_{S}\left(x_{4}\right)>\mu_{T_{2}}\left(x_{4}\right), v_{S}\left(x_{4}\right)<v_{T_{2}}\left(x_{4}\right)$, and $\mu_{S}\left(x_{4}\right)<\mu_{T_{3}}\left(x_{4}\right), v_{S}\left(x_{4}\right)>v_{T_{3}}\left(x_{4}\right)$, in the IFSs $\widetilde{S}$ and $\widetilde{T}_{3}$. Since the proposed belief and plausibility measures are constructed under weights $w_{i}$ with $\sum_{i=1}^{n} w_{i}=1$, we can choose any arbitrary values of $w_{i}$ under the condition $\sum_{i=1}^{n} w_{i}=1$. However, the responses of the proposed belief and plausibility measures remain the same for different values of $w_{i}$. Assume that weights are assigned as $w_{1}=0.1$, $w_{2}=0.3, w_{3}=0.15, w_{4}=0.25$, and $w_{5}=0.2$. The belief measures on the IFSs $\widetilde{S}_{,} \widetilde{T}_{1}, \widetilde{T}_{2}$, and $\widetilde{T}_{3}$ under the weights are $\operatorname{Bel}(\widetilde{S})=0.6175, \operatorname{Bel}\left(\widetilde{T}_{1}\right)=0.6550, \operatorname{Bel}\left(\widetilde{T}_{2}\right)=0.6050$, and
$\operatorname{Bel}\left(\widetilde{T}_{3}\right)=0.6800$. We observe that the proposed belief measure of equation (4) from $\widetilde{S} \longrightarrow \widetilde{T}_{1}$ is increasing due to increasing membership values of $\mu_{S}\left(x_{4}\right)<\mu_{\widetilde{T}}\left(x_{4}\right)$. Similarly, $\widetilde{S} \longrightarrow \widetilde{T}_{2}$ is decreasing due to $\mu_{S}\left(x_{4}\right)>\mu_{\widetilde{T}}\left(x_{4}\right)$, and $\widetilde{S} \longrightarrow \widetilde{T}_{3}$ is increasing due to $\mu_{S}\left(x_{4}\right)<\mu_{T_{3}}\left(x_{4}\right)^{2}$. Similarly, the plausibility measure on the IFSs $\widetilde{S}, \widetilde{T}_{1}, \widetilde{T}_{2}$, and $\widetilde{T}_{3}$ under the weights are $\operatorname{Pl}(\widetilde{S})=0.7650, \quad \operatorname{Pl}\left(\widetilde{T}_{1}\right)=0.7900$, $\operatorname{Pl}\left(\widetilde{T}_{2}\right)=0.7400$, and $\operatorname{Pl}\left(\widetilde{T}_{3}\right)=0.8025$. We notice that the proposed plausibility measure of equation (5) from $\widetilde{S} \longrightarrow \widetilde{T}_{1}$ is increasing due to decreasing nonmembership values of $v_{\widetilde{S}}\left(x_{4}\right)>v_{T_{1}}\left(x_{4}\right)$. Similarly, $\widetilde{S} \longrightarrow \widetilde{T}_{2}$ is decreasing due to $v_{S}\left(x_{4}\right)<v_{T^{2}}\left(x_{4}\right)$, and $\widetilde{S} \longrightarrow \widetilde{T}_{3}$ is increasing due to $v_{S}\left(x_{4}\right)>v_{T_{3}}\left(x_{4}\right)$. These descriptions about the responses of the proposed belief and plausibility measures are given in Table 1. From Table 1, the proposed method for measuring belief and plausibility responses on variations in IFSs gives reasonable results.

\section{Distance and Similarity Measures on Belief- Plausibility Intervals}

In this section, we first construct belief-plausibility intervals (BPIs) of IFSs based on the proposed Bel and Pl measures. We then use Hausdorff metric to find the distance between BPIs of IFSs. This makes it to give similarity measures between BPIs. Literally, Hausdorff metric is a measure of how 
TABLE 1: Belief and plausibility responses on variations in IFSs.

Changes in IFSs $\quad$ Belief response $\quad$ Plausibility response

\begin{tabular}{lcc}
\hline$\widetilde{S} \longrightarrow \widetilde{T}_{1}$ & I & I \\
$\widetilde{S} \longrightarrow \widetilde{T}_{2}$ & D & D \\
$\widetilde{S} \longrightarrow \widetilde{T}_{3}$ & I & I
\end{tabular}

$\mathrm{U}, \mathrm{I}$, and $\mathrm{D}$ represent unchanged, increased, and decreased, respectively.

far between two nonempty closed and bounded (compact) subsets $S$ and $T$ in a metric space that looks like each other with respect to their positions in the metric space. Hausdorff metric is defined as the maximum distance of a set to the nearest point in the other set $[26,27]$. Let $\mathrm{d}(x, y)=\|x-y\|$ be a Euclidean distance between $x$ and $y$ of two subsets $S$ and $T$ in the metric space $S$. Then, the forward distance and backward distance is given as follows:

$$
\begin{aligned}
& h(S, T)=\max _{x \in S}\left\{\min _{y \in T}(\|x-y\|)\right\}, \\
& h(S, T)=\max _{y \in T}\left\{\min _{x \in S}(\|x-y\|)\right\} .
\end{aligned}
$$

Hausdorff metric is oriented, in other words, asymmetric as well, which means that most of the time forward distance $h(S, T)$ is not equal to backward distance $h(T, S)$. Hausdorff metric is defined as

$$
H(S, T)=\max \{h(S, T), h(T, S)\} .
$$

Let us consider the real space $\mathfrak{R}$. For any two intervals $S=\left[s_{1}, s_{2}\right]$ and $T=\left[t_{1}, t_{2}\right]$, the Hausdorff metric $H(S, T)$ is given by

$$
H(S, T)=\max \left\{\left|s_{1}-t_{1}\right|,\left|s_{2}-t_{2}\right|\right\} .
$$

Let $\widetilde{S}$ and $\widetilde{T}$ be IFSs in $X=\left\{x_{1}, x_{2}, \ldots, x_{n}\right\}$. For each $x_{i} \in X$, we define the belief-plausible intervals (BPIs) of $x_{i}$ in the IFSs $\widetilde{S}$ and $\widetilde{T}$ as $i=1,2, \ldots, n$ :

$$
\begin{aligned}
& \operatorname{BPI}_{\tilde{S}}\left(x_{i}\right)=\left[\operatorname{Bel}_{S}\left(x_{i}\right), \operatorname{Pl}_{\tilde{S}}\left(x_{i}\right)\right]=\left[\mu_{S}\left(x_{i}\right), 1-v_{\mathcal{S}}\left(x_{i}\right)\right], \\
& \operatorname{BPI}_{\widetilde{T}}\left(x_{i}\right)=\left[\operatorname{Bel}_{T}\left(x_{i}\right), \operatorname{Pl}_{\widetilde{T}}\left(x_{i}\right)\right]=\left[\mu_{\widetilde{T}}\left(x_{i}\right), 1-v_{\widetilde{T}}\left(x_{i}\right)\right] .
\end{aligned}
$$

Thus, $\operatorname{BPI} \sim \sim_{S}\left(x_{i}\right)$ and $\operatorname{BPI}_{\widetilde{T}}\left(x_{i}\right)$ are subintervals in $[0,1]$. We then define the BPIs of the IFSs $\widetilde{S}$ and $\widetilde{T}$ as BPI $\left\{\operatorname{BPI}_{\tilde{S}}\left(x_{i}\right): x_{i} \in X\right\}$ and $\operatorname{BPI}_{\widetilde{T}}=\left\{\operatorname{BPI}_{\widetilde{T}}\left(x_{i}\right): x_{i} \in X\right\}$. Let $H\left(\operatorname{BPI} \sim\left(x_{i}\right), \operatorname{BPI} \sim\left(x_{i}\right)\right)$ denote Hausdorff distance between $\operatorname{BPI} \sim\left(x_{i}\right)$ and $\operatorname{BPI}_{T}\left(x_{i}\right)$. Then, we define the Hausdorff distance $\mathrm{d}_{\mathrm{BPH}}\left(\mathrm{BPI}_{\tilde{S}}, \mathrm{BPI}_{\widetilde{T}}\right)$ between the two BPIs of BPI $\mathrm{SP}_{\mathcal{S}}$ and $\mathrm{BPI}_{\bar{T}}$ as

$$
d_{\mathrm{BPH}}\left(\mathrm{BPI}_{\tilde{S}}, \mathrm{BPI}_{\tilde{T}}\right)=\frac{1}{n} \sum_{i=1}^{n} H\left(\operatorname{BPI}_{\tilde{S}}\left(x_{i}\right), \operatorname{BPI}_{\widetilde{T}}\left(x_{i}\right)\right) \text {. }
$$

We next give a definition for a distance $d$ on BPIs.

Definition 7. Let $\mathrm{BPI}_{\widetilde{S}}, \mathrm{BPI}_{\widetilde{T}}$, and $\mathrm{BPI}_{\tilde{W}}$ be the three BPIs corresponding to three IFSs $\widetilde{S}, \widetilde{T}$, and $W$ on $X$, respectively. A $d$ on BPIs is called a distance if it satisfies the following conditions:
(C1) (nonnegativity) $0 \leq d\left(\mathrm{BPI}_{\widetilde{S}}, \mathrm{BPI}_{\widetilde{T}}\right) \leq 1$;

(C2) (separability)d( $\left.\mathrm{BPI}_{\tilde{S}}, \mathrm{BPI}_{\tilde{T}}\right)=0$, if and if $\mathrm{BPI}_{\tilde{S}}=\mathrm{BPI}_{\tilde{T}}$;

(C3) (symmetric) $d\left(\mathrm{BPI}_{\tilde{S}}, \mathrm{BPI}_{\tilde{T}}\right)=d\left(\mathrm{BPI}_{\widetilde{T}}, \mathrm{BPI}_{\tilde{S}}\right)$;

(C4) (containment)If $\mathrm{BPI}_{\widetilde{S}}, \leq \mathrm{BPI}_{\widetilde{T}} \leq \mathrm{BPI}_{\widetilde{W}}$, then $d$

$$
\begin{aligned}
& \cdot\left(\mathrm{BPI}_{\tilde{S}}, \mathrm{BPI}_{\tilde{T}}\right) \leq d\left(\mathrm{BPI}_{\tilde{S}}, \mathrm{BPI}_{\tilde{W}}\right) \text { and } d\left(\mathrm{BPI}_{\tilde{T}}, \mathrm{BPI}_{\tilde{W}}\right) \\
& \leq d\left(\mathrm{BPI}_{\tilde{S}}, \mathrm{BPI}_{\tilde{W}}\right)
\end{aligned}
$$

(C5) (triangle inequality)For any $\mathrm{BPI}_{\tilde{S}}, \mathrm{BPI}_{\widetilde{T}}$ and $\mathrm{BPI}_{\tilde{W}}$,

$$
\text { then } d\left(\mathrm{BPI}_{\tilde{S}}, \mathrm{BPI}_{\tilde{W}}\right) \leq d\left(\mathrm{BPI}_{\tilde{S}}, \mathrm{BPI}_{\tilde{T}}\right)+d\left(\mathrm{BPI}_{\tilde{T}}, \mathrm{BPI}_{\tilde{W}}\right) \text {. }
$$

It is natural to ask "Is the defined distance $d_{\mathrm{BPH}}\left(\mathrm{BPI}_{\tilde{s}}, \mathrm{BPI} \widetilde{\tau}\right)$ reasonable?" To ensure the reasonability and validity of the proposed distance measure $d_{\mathrm{BPH}}$ of equation (11), we give the following theorem.

Theorem 2. Let $X=\left\{x_{1}, x_{2}, \ldots, x_{n}\right\}$ be a finite universe of discourses. The proposed distance $d_{B P H}\left(B P I_{\sim}, B P I_{\widetilde{T}}\right)$ for the two BPIs of the IFSs $\widetilde{S}$ and $\widetilde{T}$ satisfies all conditions in Definition 7.

Proof. Let $\mathrm{BPI}_{\widetilde{S}}$ and $\mathrm{BPI}_{\widetilde{T}}$ be any two BPIs on IFSs $\widetilde{S}$ and $\widetilde{T}$ in $X=\left\{x_{1}, \ldots, x_{n}\right\}$. According to $d_{\mathrm{BPH}}\left(\mathrm{BPI}_{\tilde{s}}, \mathrm{BPI}_{\widetilde{T}}\right)=$ $(1 / n) \sum_{i=1}^{n} H\left(\operatorname{BPI}_{S}\left(x_{i}\right), \operatorname{BPI}_{\sim}\left(x_{i}\right)\right)$, where $0 \leq H\left(\operatorname{BPI}_{\sim}\left(x_{i}\right)\right.$, $\left.\operatorname{BPI}_{\widetilde{T}}\left(x_{i}\right)\right) \leq 1, \forall x_{i} \in X$, due to all in absolute values. Thus, $0 \leq d_{\mathrm{BPH}}\left(\mathrm{BPI}_{\tilde{s}}, \mathrm{BPI}_{\tilde{T}}\right) \leq 1$ and the condition $(\mathrm{C} 1)$ of Definition 7 is satisfied. If $\mathrm{BPI}_{\tilde{S}}=\mathrm{BPI}_{\widetilde{T}}$, then, for every $x_{i} \in X$, $\operatorname{Bel}_{S}\left(x_{i}\right)=\operatorname{Bel}_{T}\left(x_{i}\right)$ and $\operatorname{Pl}_{\mathcal{S}}\left(x_{i}\right)=\mathrm{Pl}_{\tilde{T}}\left(x_{i}\right)$, and thus,

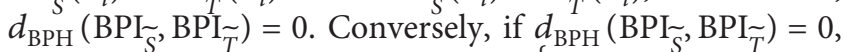
then for every $x_{i} \in X, \quad \max \left\{\left|\operatorname{Bel}_{S}\left(x_{i}\right)-\operatorname{Bel}_{T}^{T}\left(x_{i}\right)\right|\right.$, $\left.\left|\mathrm{Pl}_{S}\left(x_{i}\right)-\mathrm{Pl}_{\widetilde{T}}\left(x_{i}\right)\right|\right\}=0$. Hence, both terms $\mid \operatorname{Bel}_{S}^{T}\left(x_{i}\right)-$ $\operatorname{Bel}_{T}^{S}\left(x_{i}\right) \mid=0$ and $\left|\mathrm{Pl}_{S}\left(x_{i}\right)-\mathrm{Pl}_{\widetilde{T}}\left(x_{i}\right)\right|=0$. Then, we have that $\mathrm{BPI}_{\tilde{S}^{T}}=\mathrm{BPI}_{\tilde{T}}$. Thus, the condition (C2) is proved. Since $\max \left\{\left|\operatorname{Bel}_{S}^{\sim}\left(x_{i}\right)-\operatorname{Bel}_{\widetilde{T}}\left(x_{i}\right)\right|,\left|\mathrm{Pl}_{\tilde{S}}\left(x_{i}\right)-\mathrm{Pl}_{\widetilde{T}}\left(x_{i}\right)\right|\right\}=\max \{\mid \mathrm{Bel}$

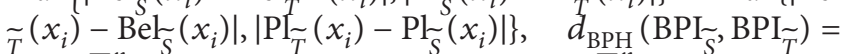
$(1 / n) \sum_{i=1}^{n} H\left(\operatorname{BPI}_{\mathcal{S}}\left(x_{i}\right), \operatorname{BPI}_{\widetilde{T}}\left(x_{i}\right)\right)=(1 / n) \sum_{i=1}^{n} H\left(\operatorname{BPI}_{\widetilde{T}}\left(x_{i}\right)\right.$, $\left.\operatorname{BPI}\left(x_{i}\right)\right)=d_{\mathrm{BPH}}\left(\mathrm{BPI}_{\tilde{T}}, \mathrm{BPI} \tilde{s}\right)$. Thus, the symmetric property (C3) is satisfied. We next prove the condition (C4) of containment property. Let $\mathrm{BPI}_{\mathcal{S}} \leq \mathrm{BPI}_{\tilde{T}} \leq \mathrm{BPI}_{\tilde{W}}$. Then, $\operatorname{Bel}_{S}\left(x_{i}\right) \leq \operatorname{Bel}_{T}\left(x_{i}\right) \leq \operatorname{Bel}_{\tilde{W}}\left(x_{i}\right)$ and $\operatorname{PF}_{S}^{T}\left(x_{i}\right) \geq \operatorname{Pl}_{T}\left(x_{i}\right) \geq$ $\mathrm{Pl}_{\tilde{W}}\left(x_{i}\right), \forall x_{i} \in X$. Thus, we have $H\left(\operatorname{BPI}_{S}\left(x_{i}\right), \operatorname{BPI}_{\tilde{W}}\left(x_{i}\right)\right)=$ $\max \left\{\left|\operatorname{Bel}_{S}\left(x_{i}\right)-\operatorname{Bel}_{\widetilde{W}}\left(x_{i}\right)\right|,\left|\mathrm{Pl}_{S}\left(x_{i}\right)-\mathrm{Pl}_{\widetilde{W}}\left(x_{i}\right)\right|\right\}, \ldots, \quad H\left(\mathrm{BPI}_{\tilde{T}}\right.$ $\left.\left(x_{i}\right), \quad \mathrm{BPI}_{\tilde{W}}\left(x_{i}\right)\right)=\max \left\{\left|\operatorname{Bel}_{T}\left(x_{i}\right)-\operatorname{Bel}_{\widetilde{W}}\left(x_{i}\right)\right|, \quad \mid \mathrm{Pl}_{\tilde{T}}\left(x_{i}\right)-\right.$ $\left.\mathrm{Pl}_{\widetilde{W}}\left(x_{i}\right) \mid\right\}$ :

(i) If $\left|\operatorname{Bel}_{\mathcal{S}}\left(x_{i}\right)-\mathrm{Bel}_{\widetilde{W}}\left(x_{i}\right)\right| \geq\left|\mathrm{Pl}_{\mathcal{S}}\left(x_{i}\right)-\mathrm{Pl}_{\widetilde{W}}\left(x_{i}\right)\right|$, then $H\left(\operatorname{BPI}_{S}\left(x_{i}\right), \mathrm{BPI}_{\tilde{W}}\left(x_{i}\right)\right)=\left|\operatorname{Bel}_{\mathcal{S}}\left(x_{i}\right)-\operatorname{Bel}_{\tilde{W}}\left(x_{i}\right)\right|$. But, we have $\left|\mathrm{Pl}_{S}^{W}\left(x_{i}\right)-\mathrm{Pl}_{\tilde{T}}\left(x_{i}\right)\right| \leq \mid \mathrm{Pl}_{S}\left(x_{i}\right)-\mathrm{Pl}_{\tilde{W}}$ $\left(x_{i}\right)|\leq| \operatorname{Bel}_{\mathcal{S}}\left(x_{i}\right)-\operatorname{Bel}_{\widetilde{W}}\left(x_{i}\right) \mid \quad$ and $\mid \mathrm{Pl}_{\tilde{T}}\left(x_{i}\right)-\mathrm{Pl}_{\tilde{W}}^{W}$ $\left(x_{i}\right)|\leq| \mathrm{Pl}_{S}\left\{\left(x_{i}\right)-\mathrm{Pl}_{\tilde{W}}\left(x_{i}\right)|\leq| \operatorname{Bel}_{S}\left(x_{i}\right)-\operatorname{Bel}_{\tilde{W}}\left(x_{i}\right) \mid\right.$. On the contrary, we have that $\mid \operatorname{Bel}_{S}\left(x_{i}\right)$ $\operatorname{Bel}_{\widetilde{T}}\left(x_{i}\right)|\leq| \operatorname{Bel} \widetilde{\mathcal{S}}\left(x_{i}\right)-\operatorname{Bel}_{\tilde{W}}\left(x_{i}\right) \mid$ and $\mid \operatorname{Bel}_{\tilde{T}}\left(x_{i}\right)-$ $\operatorname{Bel} \underset{W}{T}\left(x_{i}\right)|\leq| \operatorname{Bel} \sim \widetilde{S}\left(x_{i}\right)-\operatorname{Bel}_{\tilde{W}}\left(x_{i}\right) \mid$. On combining the above inequality equations, we obtain $H\left(\operatorname{BPI}_{\sim}\left(x_{i}\right), \operatorname{BPI}_{\widetilde{T}}\left(x_{i}\right)\right) \leq H\left(\operatorname{BPI}_{\sim}\left(x_{i}\right), \mathrm{BPI}_{\widetilde{W}}\left(x_{i}\right)\right)$ and $H\left(\operatorname{BPI}_{\widetilde{T}}\left(x_{i}\right), \operatorname{BPI}_{\widetilde{W}}\left(x_{i}\right)\right) \leq H\left(\operatorname{BPI}_{\widetilde{S}}\left(x_{i}\right), \mathrm{BPI}_{\widetilde{W}}\left(x_{i}\right)\right)$. 
Hence, it follows that $d_{\mathrm{BPH}}\left(\mathrm{BPI}_{\widetilde{S}}, \mathrm{BPI}_{\widetilde{T}}\right) \leq d_{\mathrm{BPH}}$ $\left(\mathrm{BPI}_{\tilde{S}}, \mathrm{BPI}_{\tilde{W}}\right)$ and $d_{\mathrm{BPH}}\left(\mathrm{BPI}_{\widetilde{T}}, \mathrm{BPI}_{\widetilde{W}}\right)^{\leq} \leq d_{\mathrm{BPH}}\left(\mathrm{BPI}_{\tilde{S}}\right.$, $\operatorname{BPI} \widetilde{W})$.

(ii) If $\left|\operatorname{Bel}_{S}\left(x_{i}\right)-\mathrm{Bel}_{\widetilde{W}}\left(x_{i}\right)\right| \leq\left|\mathrm{Pl}_{S}\left(x_{i}\right)-\mathrm{Pl}_{\widetilde{W}}\left(x_{i}\right)\right|$, then $H\left(\mathrm{BPI}_{\mathcal{S}}\left(x_{i}\right), \mathrm{BPI}_{\tilde{W}}\left(x_{i}\right)\right)=\left|\mathrm{PI}_{\mathcal{S}}\left(x_{i}\right)-\mathrm{PI}_{\tilde{W}}\left(x_{i}\right)\right|$, but we have $\left|\operatorname{Bel}_{S}\left(x_{i}\right)-\operatorname{Bel}_{\widetilde{T}}^{\sim}\left(x_{i}\right)\right| \leq \mid \operatorname{Bel}_{S}\left(x_{i}\right)-\operatorname{Bel}_{\tilde{W}}$ $\left(x_{i}\right)|\leq| \mathrm{Pl}_{S}\left(x_{i}\right)^{S}-\left.\mathrm{Pl}_{\tilde{W}}\left(x_{i}\right)\right|^{\top}$ and $\mid \operatorname{Bel}_{\tilde{T}}^{S}\left(x_{i}\right)-\operatorname{Bel}_{\tilde{W}}$ $\left(x_{i}\right)|\leq| \operatorname{Bel}_{S}\left(x_{i}\right)-\operatorname{Bel}_{\widetilde{W}}\left(x_{i}\right)|\leq| \mathrm{Pl}_{S}\left(x_{i}\right)-\mathrm{Pl}_{\widetilde{W}}\left(x_{i}\right) \mid$. On the contrary, $\left|\mathrm{Pl}_{S}\left(x_{i}\right)-\mathrm{PI}_{T}\left(x_{i}\right)\right| \leq \mid \mathrm{Pl}_{S}\left(x_{i}\right)-$ $\mathrm{Pl}_{\widetilde{W}}\left(x_{i}\right) \mid$ and $\left|\mathrm{Pl}_{\widetilde{T}}\left(x_{i}\right)-\mathrm{Pl}_{\tilde{W}}\left(x_{i}\right)\right| \leq \mid \mathrm{Pl}_{S}\left(x_{i}\right)-$ $\mathrm{Pl}_{\widetilde{W}}\left(x_{i}\right) \mid$. On combining the above inequalities, we have $H\left(\operatorname{BPI}_{\mathcal{S}}\left(x_{i}\right), \operatorname{BPI}_{\widetilde{T}}\left(x_{i}\right)\right) \leq H\left(\operatorname{BPI}_{\mathcal{S}}\left(x_{i}\right), \mathrm{BPI}_{\tilde{W}}\right.$ $\left.\left(x_{i}\right)\right)$ and $H\left(\operatorname{BPI}_{T}\left(x_{i}\right), \operatorname{BPI}_{\widetilde{W}}\left(x_{i}\right)\right) \leq H\left(\operatorname{BPI}_{\mathcal{S}}\left(x_{i}\right)\right.$, $\left.\mathrm{BPI}_{\widetilde{W}}\left(x_{i}\right)\right)$. Hence, it follows that $d_{\mathrm{BPH}}\left(\mathrm{BPI}_{\tilde{S}}, \mathrm{BPI}_{\tilde{T}}\right) \leq$ $d_{\mathrm{BPH}}\left(\mathrm{BPI}_{\tilde{S}}, \mathrm{BPI} \tilde{\widetilde{W}}\right)$ and $d_{\mathrm{BPH}}\left(\mathrm{BPI}_{\tilde{T}}, \mathrm{BPI} \tilde{W}_{\tilde{W}}\right) \leq d_{\mathrm{BPH}}$ $\left(\mathrm{BPI}_{\tilde{S}}, \mathrm{BPI} \mathrm{W}_{\tilde{W}}\right)$. Thus, (i) and (ii) completes the proof. Next, we prove triangle inequality. We show that, for any $\mathrm{BPI}_{\tilde{S}}, \mathrm{BPI}_{\tilde{T}}$, and $\mathrm{BPI}_{\tilde{W}}$, we have belief degrees $\operatorname{Bel}_{S}\left(x_{i}\right), \operatorname{Bel}_{T}\left(x_{i}\right)$, and $\operatorname{Bel}_{\widetilde{W}}\left(x_{i}\right)$ and plausible degrees $\mathrm{Pl}_{S}\left(x_{i}\right), \mathrm{Pl}_{T}^{T}\left(x_{i}\right)$, and $\mathrm{Pl}_{\tilde{W}}\left(x_{i}\right)$, respectively.

(iii) If $\left|\operatorname{Bel}_{S}\left(x_{i}\right)-\operatorname{Bel}_{\widetilde{W}}\left(x_{i}\right)\right| \geq\left|\mathrm{Pl}_{S}\left(x_{i}\right)-\mathrm{Pl}_{\tilde{W}}\left(x_{i}\right)\right|$, then $H\left(\operatorname{BPI}_{\mathcal{S}}\left(x_{i}\right), \operatorname{BPI}_{\widetilde{W}}\left(x_{i}\right)\right)=\left|\operatorname{Bel}_{S}\left(x_{i}\right)-\operatorname{Bel}_{\widetilde{W}}\left(x_{i}\right)\right|$. $H\left(\operatorname{BPI}_{\tilde{S}}\left(x_{i}\right), \operatorname{BPI}_{\widetilde{W}}\left(x_{i}\right)\right)=\mid \operatorname{Bel}_{S} \quad\left(x_{i}\right)-\operatorname{Bel}_{T}\left(x_{i}\right)+$ $\operatorname{Bel}_{T}\left(x_{i}\right)-\operatorname{Bel}_{\tilde{W}} \quad\left(x_{i}\right)|\leq| \operatorname{Bel}_{\tilde{S}}\left(x_{i}\right)-\operatorname{Bel}_{T}\left(x_{i}\right) \mid+$ $\left|\operatorname{Bel}_{\widetilde{T}}\left(x_{i}\right)-\operatorname{Bel}_{\widetilde{W}}\left(x_{i}\right)\right|=\max \left\{\left|\operatorname{Bel}_{S}\left(x_{i}\right)-\operatorname{Bel}_{\widetilde{T}}\left(x_{i}\right)\right|\right.$, $\left.\left|\mathrm{Pl}_{S}\left(x_{i}\right)-\mathrm{Pl}_{\tilde{T}}\left(x_{i}\right)\right|\right\}+\max \left\{\left|\operatorname{Bel}_{\tilde{T}}\left(x_{i}\right)-\operatorname{Bel}_{\tilde{W}}\left(x_{i}\right)\right|\right.$, $\left.\left|\mathrm{Pl}_{\tilde{T}}\left(x_{i}\right)-\mathrm{Pl}_{\widetilde{W}}\left(x_{i}\right)\right|\right\}=H\left(\mathrm{BPI}_{\mathcal{S}}\left(x_{i}\right), \mathrm{BPI}_{\widetilde{T}}\left(x_{i}\right)\right)+$ $H\left(\mathrm{BPI}_{\widetilde{T}}\left(x_{i}\right), \mathrm{BPI}_{\widetilde{W}}\left(x_{i}\right)\right)=d_{\mathrm{BPH}}\left(\mathrm{BPI}_{\tilde{S}}, \mathrm{BPI}_{\tilde{T}}\right)+$ $d_{\mathrm{BPH}}\left(\mathrm{BPI}_{\widetilde{T}}, \mathrm{BPI} \widetilde{W}\right)$.

(iv) Similarly, $\quad$ if $\left|\operatorname{Bel}_{S}\left(x_{i}\right)-\operatorname{Bel}_{\tilde{W}}\left(x_{i}\right)\right| \leq \mid \operatorname{Pl}_{S}\left(x_{i}\right)-$ $\mathrm{Pl}_{\widetilde{W}}\left(x_{i}\right) \mid$, then $H\left(\mathrm{BPI}_{\mathcal{S}}\left(x_{i}\right), \mathrm{BPI}_{\widetilde{W}}\left(x_{i}\right)\right)=\mid \mathrm{PI}_{S}\left(x_{i}\right)-$ $\mathrm{Pl}_{\widetilde{W}}\left(x_{i}\right)\left|. \quad H\left(\mathrm{BPI}_{\tilde{S}}\left(x_{i}\right), \mathrm{BPI}_{\tilde{W}}\left(x_{i}\right)\right)=\right| \mathrm{Pl}_{S} \quad\left(x_{i}\right)-$ $\mathrm{Pl}_{\tilde{T}}^{\sim}\left(x_{i}\right)+\mathrm{Pl}_{\tilde{T}}\left(x_{i}\right)-\mathrm{Pl}_{\widetilde{W}}\left(x_{i}\right)|\leq| \mathrm{Pl}_{S}\left(x_{i}\right)-\mathrm{Pl}_{\widetilde{T}}\left(x_{i}\right) \mid+$ $\left|\mathrm{Pl}_{T}\left(x_{i}\right)-\mathrm{Pl}_{\widetilde{W}}\left(x_{i}\right)\right|=\max \left\{\left|\operatorname{Bel}_{S}\left(x_{i}\right)-\operatorname{Bel}_{T}\left(x_{i}\right)\right|\right.$,
$\left.\left|\mathrm{Pl}_{S}\left(x_{i}\right)-\mathrm{Pl}_{\widetilde{T}}\left(x_{i}\right)\right|\right\}+\max \left\{\left|\operatorname{Bel}_{\tilde{T}}\left(x_{i}\right)-\operatorname{Bel}_{\widetilde{W}}\left(x_{i}\right)\right|\right.$, $\left.\left|\mathrm{Pl}_{\tilde{T}}\left(x_{i}\right)-\mathrm{Pl}_{\tilde{W}}\left(x_{i}\right)\right|\right\}=H\left(\operatorname{BPI}_{\tilde{S}}\left(x_{i}\right), \quad \operatorname{BPI}_{\tilde{T}}\left(x_{i}\right)\right)+$ $H\left(\mathrm{BPI}_{\widetilde{T}}\left(x_{i}\right), \mathrm{BPI}_{\widetilde{W}}\left(x_{i}\right)\right)=d_{\mathrm{BPH}}\left(\mathrm{BPI}_{\tilde{S}}, \mathrm{BPI}_{\widetilde{T}}\right)+d_{\mathrm{BPH}}$ $\left(\mathrm{BPI}_{\tilde{T}}, \mathrm{BPI} \tilde{W}_{\tilde{W}}\right)$. It follows that $d_{\mathrm{BPH}}\left(\mathrm{BPI}_{\tilde{S}}, \mathrm{BPI}_{\tilde{W}}\right) \leq$ $d_{\mathrm{BPH}}\left(\mathrm{BPI}_{\tilde{S}}, \mathrm{BPI}_{\widetilde{T}}\right)+d_{\mathrm{BPH}}\left(\mathrm{BPI}_{\widetilde{T}}, \mathrm{BPI}_{\tilde{W}}\right)$. From (iii) and (iv), we obtain the property (C5).

In applications and ranking of alternatives, a weight vector $\widetilde{w}$ of an element $x \in X$ is usually considered. Therefore, we use equation (11) to establish a weighted Hausdorff distance between two BPIs BPI $\sim_{S}$ and BPI $\sim$ on IFS. Suppose that the weight of each element $x_{i} \in X$ is $\widetilde{w}_{i}(i=$ $1,2,3, \ldots, n)$ such that $\sum_{i=1}^{n} \widetilde{w}_{i}=1$, where $0 \leq \widetilde{w}_{i} \leq 1$, then the weight belief and plausible Hausdorff distance is given as follows:

$$
d_{w \mathrm{BPH}}\left(\operatorname{BPI}_{\widetilde{S}}, \mathrm{BPI}_{\widetilde{T}}\right)=\sum_{i=1}^{n} \widetilde{w}_{i} H\left(\operatorname{BPI}_{\widetilde{S}}\left(x_{i}\right), \operatorname{BPI}_{\widetilde{T}}\left(x_{i}\right)\right) .
$$

Remark 1. Equation (13) becomes equation (11) if we replace $\widetilde{w}_{i}=(1 / n)$, for $i=1,2, \ldots, n$. Consequently, equation (11) becomes a special case of equation (13).

Property 1. Let $d_{\mathrm{BPH}}\left(\mathrm{BPI}_{\vec{S}}, \mathrm{BPI}_{\widetilde{T}}\right)$ be the distance between two BPIs BPI $\sim \vec{s}$ and $\mathrm{BPI}_{\tilde{T}}$ of IFSs. The similarity measures $s$ between them can be denoted by $s\left(\mathrm{BPI}_{\tilde{S}}, \mathrm{BPI}_{\tilde{T}}\right)=1-d_{\mathrm{BPH}}\left(\mathrm{BPI}_{\tilde{S}}, \mathrm{BPI}_{\tilde{T}}\right)$.

Property 2. For three BPIs $\mathrm{BPI}_{\tilde{S}}, \mathrm{BPI}_{\tilde{T}}$, and $\mathrm{BPI}_{\tilde{W}}$ of IFSs with $\mathrm{BPI}_{\mathcal{S}} \subseteq \mathrm{BPI}_{\tilde{T}} \subseteq \mathrm{BPI} \tilde{W}$, we have $d_{\mathrm{BPH}}\left(\mathrm{BPI}_{\tilde{S}}, \mathrm{BPI}_{\tilde{W}}\right)$ $\geq \max \left\{d_{\mathrm{BPH}}\left(\mathrm{BPI}_{\widetilde{S}}, \mathrm{BPI}_{\widetilde{T}}\right), d_{\mathrm{BPH}}\left(\mathrm{BPI}_{\tilde{T}}, \mathrm{BPI}_{\widetilde{W}}\right)\right\}$.

Property 3. For any two BPIs $\mathrm{BPI}_{\tilde{S}}$ and $\mathrm{BPI}_{\tilde{T}}$ of IFSs, the forward and backward Hausdorff distances obey either symmetric or asymmetric property, i.e.,

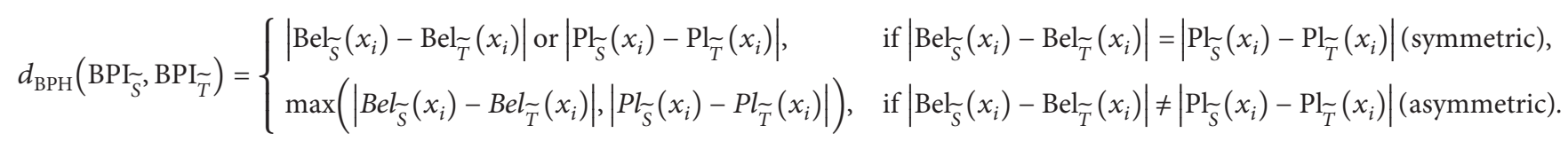

We also define the linguistic terms like dilation (DIL) and concentration (CON) as follows.

Definition 8. Let $\widetilde{S}=\left\{\left\langle x, \mu_{S}(x), v_{S}(x)\right\rangle: x \in X\right\}$ be an IFS on $X$. For any positive real number $n$, the IFS $\widetilde{S}^{n}$ is defined as $\widetilde{S}^{n}=\left\{\left\langle x,\left[\mu_{S}(x)\right]^{n},\left[1-v_{S}(x)\right]^{n}\right\rangle: x \in X\right\}$. The corresponding BPIs can be defined as

$$
\left(\operatorname{BPI}_{S}\right)^{n}=\left\{\left\langle x,\left[\left(\operatorname{Bet}_{S}(x)\right)^{n},\left(\operatorname{Pr}_{S}(x)\right)^{n}\right]\right\rangle: x \in X\right\}, \quad n>0,
$$

where $\operatorname{Bet}_{S}(x)=\mu_{S}(x)$ and $\operatorname{Pl}_{S}(x)=1-{\nu_{S}}_{S}(x)$.
Using Definition 8, the concentration and dilation of a $\mathrm{BPI}_{\tilde{S}}$ corresponding to an IFS $\widetilde{S}$ in the context of DST can be defined as follows:

$$
\operatorname{CON}\left(\operatorname{BPI}_{\tilde{s}}^{-}\right)=\left\{\left\langle x,\left[\operatorname{Bel} \underset{\operatorname{CON}\left(\operatorname{BPr}_{s}\right)}{ }(x), \mathrm{Pl}_{\operatorname{CON}\left(\mathrm{BPL}_{s}\right)}(x)\right]\right\rangle: x \in X\right\},
$$

where $\operatorname{Bel}_{\mathrm{CON}\left(\mathrm{BPF}_{s}\right)}(x)=\left(\operatorname{Bel}_{\mathrm{BPF}_{s}}(x)\right)^{2}$ and $\mathrm{Pl}_{\mathrm{CON}\left(\mathrm{BPF}_{s}\right)}(x)=$ $\left(\mathrm{Pl}_{\mathrm{BPF}}(x)\right)^{2}$. 


$$
\operatorname{DIL}\left(\mathrm{BPI}_{\tilde{s}}\right)=\left\{\left\langle x,\left[\operatorname{Bel}_{\operatorname{DIL}\left(\mathrm{BPF}_{s}\right)}(x), \operatorname{Pl} \underset{\mathrm{DIL}}{\mathrm{BPP}_{s}}(x)\right]\right\rangle: x \in X\right\},
$$

where $\quad \operatorname{Bel}_{\mathrm{DIL}(\mathrm{BPH})}(x)=\left(\operatorname{Bel}_{\mathrm{BPH}}(x)\right)^{1 / 2} \quad$ and $\mathrm{Pl}_{\mathrm{CON}(\mathrm{BPH})}(x)=\left(\mathrm{Pl}_{\mathrm{BPF}}(x)\right)^{1 / 2}$.

Similârity measurês play a vital role to differentiate between two sets or objects. Similarity has a lot of applications in many areas. It is well known that the distance and similarity measures are dual concept. Therefore, we next use the Hausdorff distance between two BPIs $\mathrm{BPI}_{\tilde{S}}$ and $\mathrm{BPI}_{\tilde{S}}$ of IFSs to define similarity between them. Let $f$ be a monotone decreasing function and $\mathrm{BPI}_{\tilde{S}}$ and $\mathrm{BPI}_{\tilde{S}}$ be two BPIs. Since $0 \leq d_{\mathrm{BPH}}\left(\mathrm{BPI}_{\widetilde{S}}, \mathrm{BPI}_{\widetilde{T}}\right) \leq 1, \quad f(1) \leq f\left(d_{\mathrm{BPH}}\left(\mathrm{BPI}_{\widetilde{S}}, \mathrm{BPI}_{\tilde{T}}\right)\right)$ $\leq f(0)$, this implies $0 \leq\left(\left(f\left(d_{\mathrm{BPH}}\left(\mathrm{BPI}_{\widetilde{S}}, \mathrm{BPI}_{\tilde{T}}\right)\right)-\right.\right.$ $f(1)) /(f(0)-f(1))) \leq 1$. Hence, the similarity measure between $\mathrm{BPI}_{\tilde{S}}$ and $\mathrm{BPI}_{\tilde{T}}$ can be defined as follows:

$$
s(\widetilde{S}, \widetilde{T})=\frac{f\left(d_{\mathrm{BPH}}\left(\mathrm{BPI}_{\tilde{S}}, \mathrm{BPI}_{\tilde{T}}\right)\right)-f(1)}{f(0)-f(1)} .
$$

By using equation (18), different kinds of similarity measures can be obtained by choosing an appropriate function $f$. The most simplest function $f$ may be chosen as a linear $f(x)=1-x$. Then, the similarity measure between $\mathrm{BPI}_{\tilde{S}}$ and $\mathrm{BPI}_{\tilde{T}}$ of IFSs can be obtained by equation (11) as follows:

$$
s_{L}(\widetilde{S}, \widetilde{T})=1-d_{\mathrm{BPH}}\left(\mathrm{BPI}_{\widetilde{S}}, \mathrm{BPI}_{\widetilde{T}}\right) .
$$

Again, we may also choose another suitable function as a simple rational function $f(x)=(1 /(1+x))$. Then, similarity measure between $\mathrm{BPI}_{S}$ and $\mathrm{BPI}_{\bar{T}}$ of IFSs can be defined as follows:

$$
s_{Q}\left(\mathrm{BPI}_{\tilde{\mathcal{S}}}, \mathrm{BPI}_{\tilde{T}}\right)=\frac{1-d_{\mathrm{BPH}}\left(\mathrm{BPI}_{\tilde{\mathcal{S}}}, \mathrm{BPI}_{\tilde{T}}\right)}{1+d_{\mathrm{BPH}}\left(\mathrm{BPI}_{\tilde{\mathcal{S}}}, \mathrm{BPI}_{\tilde{T}}\right)} .
$$

Now, we consider the well-known exponential function $f(x)=e^{-x}$ due to its diverse applications and high usefulness in dealing with a similarity relation [28], Shannon entropy [29], correlation coefficient [30], cluster analysis [31], and multicriteria decision-making [32, 33]. Therefore, we can construct other similarity measures between $\mathrm{BPI}_{\tilde{s}}$ and $\mathrm{BPI}_{\tilde{T}}$ of IFSs by using exponential function as follows:

$$
s_{E}(\widetilde{S}, \widetilde{T})=\frac{e^{-d_{\mathrm{BPH}}\left(\underset{S}{\mathrm{BPF}_{\mathrm{T}} \mathrm{BPL}}\right)}-e^{-1}}{1-e^{-1}} .
$$

We next present some numerical examples to validate effectiveness of the proposed similarity measures of equations (19)-(21).

Example 3. Let $X=\left\{x_{1}, x_{2}, x_{3}\right\}$ be the universe of discourses, and suppose that there are three patterns as $\widetilde{S}_{1}=\left\{\left\langle x_{1}, 0.7,0.2\right\rangle,\left\langle x_{2}, 0.5,0.3\right\rangle,\left\langle x_{3}, 0.2,0.5\right\rangle\right\}$,

$\widetilde{S}_{2}=\left\{\left\langle x_{1}, 0.2,0.4\right\rangle,\left\langle x_{2}, 0.6,0.3\right\rangle,\left\langle x_{3}, 0.7,0.2\right\rangle\right\}$,

$\widetilde{S}_{3}=\left\{\left\langle x_{1}, 0.2,0.3\right\rangle,\left\langle x_{2}, 0.4,0.2\right\rangle,\left\langle x_{3}, 0.5,0.1\right\rangle\right\}$.

and

Assume that a sample $\widetilde{T}$ is given as $\widetilde{T}=\left\{\left\langle x_{1}, 0.2,0.3\right\rangle,\left\langle x_{2}, 0.4,0.2\right\rangle,\left\langle x_{3}, 0.6,0.1\right\rangle\right\}$. Then, the corresponding BPIs BPI $\tilde{S}_{1}, \mathrm{BPI}_{\widetilde{S}_{2}}, \mathrm{BPI}_{\tilde{S}_{3}}$, and BPI $\tilde{\tau}_{T}$ of $\widetilde{S}_{1}, \widetilde{S}_{2}, \widetilde{S}_{3}$, and $\widetilde{T}$ are as follows: $\mathrm{BPI}_{\tilde{S}_{1}}=\left\{\left\langle x_{1},[0.7,0.8]\right\rangle\right.$, $\left.\left\langle x_{2},[0.5,0.7]\right\rangle,\left\langle x_{3},[0.2,0.5]\right\rangle\right\}, \quad \mathrm{BPI}_{\tilde{S}_{2}}=\left\{\left\langle x_{1},[0.2,0.6]\right\rangle\right.$, $\left.\left\langle x_{2},[0.6,0.7]\right\rangle,\left\langle x_{3},[0.7,0.8]\right\rangle\right\}, \quad \mathrm{BPI}_{S_{3}}=\left\{\left\langle x_{1},[0.2,0.7]\right\rangle\right.$, $\left.\left\langle x_{2},[0.4,0.8]\right\rangle,\left\langle x_{3},[0.5,0.9]\right\rangle\right\}, \quad$ and $\mathrm{BPI}_{\widetilde{T}}=\left\{\left\langle x_{1},[0.2,0.7]\right\rangle,\left\langle x_{2},[0.6,0.8]\right\rangle,\left\langle x_{3},[0.6,0.9]\right\rangle\right\}$. By using equations (19)-(21), we have

$$
\begin{aligned}
& s_{L}\left(\mathrm{BPI}_{\tilde{S}_{1}}, \mathrm{BPI}_{\tilde{T}}\right)=0.667, \\
& s_{L}\left(\mathrm{BPI}_{\tilde{S}_{2}}, \mathrm{BPI}_{\tilde{T}}\right)=0.867 \text {, } \\
& s_{L}\left(\mathrm{BPI}_{\tilde{S}_{3}}, \mathrm{BPI}_{\tilde{T}}\right)=0.967 \text {, } \\
& s_{Q}\left(\mathrm{BPI}_{\tilde{S}_{1}}, \mathrm{BPI}_{\widetilde{T}}\right)=0.500 \text {, } \\
& s_{Q}\left(\mathrm{BPI}_{\tilde{S}_{2}}, \mathrm{BPI}_{\tilde{T}}\right)=0.765 \text {, } \\
& s_{Q}\left(\mathrm{BPI}_{\tilde{S}_{3}}, \mathrm{BPI}_{\tilde{T}}\right)=0.936 \text {, } \\
& s_{E}\left(\mathrm{BPI}_{\tilde{S}_{1}}, \mathrm{BPI}_{\tilde{T}}\right)=0.552 \text {, } \\
& s_{E}\left(\mathrm{BPI}_{\tilde{S}_{2}}, \mathrm{BPI}_{\tilde{T}}\right)=0.803 \text {, } \\
& s_{E}\left(\mathrm{BPI}_{\mathcal{S}_{3}}, \mathrm{BPI}_{\widetilde{T}}\right)=0.949 .
\end{aligned}
$$

Based on above results, we can see that the sample BPI $\tilde{T}_{\tilde{T}}$ is similar to the pattern $\mathrm{BPI}_{\widetilde{s}}$ according to the principle of maximum degree of similarity between two BPIs on IFSs. The above results reflect that the belief of $\mathrm{BPI}_{\tilde{S}_{2}}$ and $\mathrm{BPI}_{\tilde{T}}$ is more similar on certain objects than the belief of $\mathrm{BPI}_{\widetilde{S}_{1}}$ and $\mathrm{BPI}_{\tilde{T}}$ and the belief of $\mathrm{BPI}_{\widetilde{S}_{2}}$ and $\mathrm{BPI}_{\tilde{T}}$, respectively.

Example 4. Suppose that there are three IFS patterns in the universe $X=\left\{x_{1}, x_{2}, x_{3}\right\}$ of discourses as follows: $\widetilde{S}_{1}=$ $\left\{\left\langle x_{1}, 0.4,0.4\right\rangle,\left\langle x_{2}, 0.3,0.3\right\rangle,\left\langle x_{3}, 0.2,0.2\right\rangle\right\} ; \quad \widetilde{S}_{2}=$ $\left\{\left\langle x_{1}, 0.3,0.3\right\rangle,\left\langle x_{2}, 0.3,0.3\right\rangle,\left\langle x_{3}, 0.3,0.3\right\rangle\right\} ; \quad \widetilde{S}_{3}=$ $\left\{\left\langle x_{1}, 0.2,0.2\right\rangle,\left\langle x_{2}, 0.2,0.2\right\rangle,\left\langle x_{3}, 0.2,0.2\right\rangle\right\}$. Assume that a sample is given as $\widetilde{T}=\left\{\left\langle x_{1}, 0.4,0.4\right\rangle,\left\langle x_{2}, 0.3,0.3\right\rangle\right.$, $\left.\left\langle x_{3}, 0.2,0.2\right\rangle\right\}$. Then, the corresponding BPIs BPI $\widetilde{S}_{1}, \mathrm{BPI} \tilde{S}_{\tilde{S}}$, $\mathrm{BPI}_{\widetilde{S}}$, and $\mathrm{BPI}_{\widetilde{T}}$ of $\widetilde{S}_{1}, \widetilde{S}_{2}, \widetilde{S}_{3}$, and $\widetilde{T}$ are displayed as follows: $\operatorname{BPI}_{S_{S}}^{S_{3}}=\left\{\left\langle x_{1},[0.4,0.6]\right\rangle,\left\langle x_{2},[0.3,0.7]\right\rangle,\left\langle x_{3},[0.2,0.8]\right\rangle\right\}$, $\mathrm{BPI}_{S_{S}}^{S_{1}}=\left\{\left\langle x_{1},[0.3,0.7]\right\rangle,\left\langle x_{2},[0.3,0.7]\right\rangle,\left\langle x_{3},[0.3,0.7]\right\rangle\right\}$, $\mathrm{BPI}_{S_{S_{3}}}=\left\{\left\langle x_{1},[0.2,0.8]\right\rangle,\left\langle x_{2},[0.2,0.8]\right\rangle,\left\langle x_{3},[0.2,0.8]\right\rangle\right\}$, and $^{S_{3}} \quad \mathrm{BPI}_{\tilde{T}}=\left\{\left\langle x_{1},[0.4,0.6]\right\rangle,\left\langle x_{2},[0.3,0.7]\right\rangle\right.$, $\left.\left\langle x_{3},[0.2,0.8]\right\rangle\right\}$. By using equations (19)-(21), we have $s_{L}\left(\mathrm{BPI}_{\tilde{S}}, \mathrm{BPI}_{\widetilde{T}}\right)=1$, $s_{L}\left(\mathrm{BPI}_{\mathrm{S}_{3}}, \mathrm{BPI}_{\widetilde{T}}\right)=0.900$, $s_{Q}\left(\mathrm{BPI}_{\tilde{S}}, \mathrm{BPI}_{\tilde{T}}\right)=0.874$, $s_{E}\left(\mathrm{BPI}^{S_{2}}, \mathrm{BPI} \sim\right)=1, \quad s_{\mathrm{T}}\left(\mathrm{BPI}_{\mathcal{Q}}\left(\mathrm{BPI}_{\tilde{S}_{3}}, \mathrm{BPI}_{\widetilde{T}}\right)=0.818\right.$, $s_{E}\left(\mathrm{BPI}_{\tilde{S}_{1}}, \mathrm{BPI}_{\tilde{T}}\right)=1, \quad s_{E}\left(\mathrm{BPI}_{\tilde{S}_{S}}, \mathrm{BPI}_{\tilde{T}}\right)=0.898, \quad$ and
$s_{E}\left(\mathrm{BPI}_{\tilde{S}}, \mathrm{BPI} \tilde{T}_{T}\right)=0.850$. From above results, the sample $\mathrm{BPI}_{T}$ is the same as the pattern $\mathrm{BPI}_{\tilde{S}_{1}}$ according to principle of the maximum degree of similarity between two BPIs. The 
above results clearly indicated that the sets $\widetilde{S}_{1}$ and $\widetilde{T}$ are exactly the same that actually match the true state.

We have shown the applicability and reliability of the proposed similarity measures by Examples 3 and 4. Furthermore, we find that the proposed similarity measures on BPIs of IFSs are suitable and well suited in the intuitionistic fuzzy environment using the context of DST. We next construct a novel belief-plausibility TOPSIS and then give its application to multicriteria decision-making.

\section{On Construction of Belief- Plausibility TOPSIS}

Group decision making is considered as the cognitive process resulting in a selection of belief or a course of action among several alternatives. For human being, decisionmaking is a sort of daily activity. In multicriteria decisionmaking (MCDM) process [29], we rank and then select the best alternative from available finite set of alternatives. It plays a key role in most fields. Impreciseness is a real truth of daily life which requires close attention in matters of management and decisions. In real-life setting with decision-making process, information available is often uncertain, vague, or imprecise. We need a powerful tool to solve decision-making problems involving uncertain, vague, or imprecise information with high precision. Therefore, we employ BPIs of IFSs to amicably tackle problems involving complex decision-making processes. In this section, we utilize similarity measures between BPIs of IFSs which provides us an opportunity to solve MCDM problems by using technique for order preference by similarity to an ideal solution (TOPSIS) [29] which is an approach to identify an alternative that is closest to the positive-ideal solution and farthest to the negative-ideal solution. We extend the concept of TOPSIS [29] to construct the belief-plausibility TOPSIS with BPIs of IFSs to solve MCDM problems.

$$
\widetilde{D}=\left(\widetilde{b}_{i j}\right)_{m \times n}=\begin{gathered}
A_{1} \\
A_{2} \\
\vdots \\
A_{m}
\end{gathered}\left[\begin{array}{c}
{\left[\mathrm{Bel}_{11}, \mathrm{Pl}_{11}\right]} \\
{\left[\mathrm{Bel}_{21}, \mathrm{Pl}_{21}\right]} \\
\vdots \\
{\left[\mathrm{Bel}_{m 1}, \mathrm{Pl}_{m 1}\right]}
\end{array}\right.
$$

Step 2: determination of the weights of criteria

In this step, we calculate criteria weights. The weights can be obtained by different ways. Suppose that the weights of criteria $C_{j}\{j=1,2, \ldots, n\}$ are $\widetilde{w}_{j}, j=1,2,3, \ldots, n$ with $\sum_{j=1}^{n} \widetilde{w}_{j}=1$ for $0 \leq \widetilde{w}_{j} \leq 1$. Since the criteria weights are completely unknown, we propose a new weighting method on the basis of belief and plausibility values as follows:
In the following, we propose a new method to solve MCDM problems with unknown criteria weights. The proposed similarity measures between BPIs of IFSs are used to measure the similarity between each alternative $A_{i}$ from belief-plausible negative-ideal solution (BPNIS) and beliefplausible positive-ideal solution (BPPIS), respectively. Then, the idea of the TOPSIS method is utilized to rank alternatives. We present a stepwise algorithm for the proposed belief-plausible TOPSIS method (BP-TOPSIS). Let the set of alternatives be denoted by $A=\left\{A_{1}, A_{2}, \ldots, A_{m}\right\}$ and the set of criteria of the alternative $A_{i}\{i=1,2, \ldots, m\}$ be represented by $C_{j}\{j=1,2, \ldots, n\}$. The purpose of this problem is to choose the best alternatives out of alternatives. The steps for the proposed BP-TOPSIS are as follows:

Step 1: construction of belief-plausible decision matrix Suppose that $A=\left\{A_{1}, A_{2}, \ldots, A_{m}\right\}$ is a set of alternatives on criteria $C=\left\{C_{1}, C_{2}, \ldots, C_{n}\right\}$. Assume that the decision matrix in IFSs is $\widetilde{D}^{*}=\left(\widetilde{a}_{i j}\right)_{m \times n}=\left(\left\langle u_{i j}, v_{i j}\right\rangle\right)$ with its corresponding belief-plausible decision matrix (BPDM) $\widetilde{D}=\left[\widetilde{b}_{i j}\right]_{m \times n}$ that is constructed by using BPIs of IFSs for properly handling MCDM problems as follows:

$$
\widetilde{D}=\left[\widetilde{b}_{i j}\right]_{m \times n}=\left[\mathrm{Bel}_{i j}, \mathrm{Pl}_{i j}\right]
$$

where $\mathrm{Bel}_{i j}=u_{i j}$ and $\mathrm{Pl}_{i j}=1-v_{i j}$.

The values $\mathrm{Bel}_{i j}=u_{i j}$ denote degrees of belief, and $v_{i j}$ represent degrees of doubt. We use $\mathrm{Pl}_{i j}=1-v_{i j}$ to represent degrees of plausibility against the alternative $A_{i}$ to the criteria $C_{j}$ such that the conditions of $0 \leq \mathrm{Bel}_{i j} \leq 1,0 \leq \mathrm{Pl}_{i j} \leq 1$, and $0 \leq \mathrm{Bel}_{i j} \leq \mathrm{Pl}_{i j} \leq 1$, with $i=$ $1,2, \ldots, m$ and $j=1,2, \ldots, n$, are satisfied. Therefore, the BPDM $\widetilde{D}=\left(\widetilde{b}_{i j}\right)_{m \times n}$ can be constructed as follows:
$\left.\begin{array}{ccc}\left.\mathrm{Cel}_{12}, \mathrm{Pl}_{12}\right] & \cdots & {\left[\mathrm{Bel}_{1 n}{ }^{C_{n}}, \mathrm{Pl}_{1 n}\right]} \\ {\left[\mathrm{Bel}_{22}, \mathrm{Pl}_{22}\right]} & \cdots & {\left[\mathrm{Bel}_{2 n}, \mathrm{Pl}_{2 n}\right]} \\ \vdots & \vdots & \vdots \\ {\left[\mathrm{Bel}_{m 2}, \mathrm{Pl}_{m 2}\right]} & \cdots & {\left[\mathrm{Bel}_{m n}, \mathrm{Pl}_{m n}\right]}\end{array}\right]$

$$
\widetilde{w}_{j}=\frac{\left(\left(3 \mathrm{Bel}_{j}+\mathrm{Pl}_{j}\right) / 2\right)}{\sum_{j=1}^{n}\left(\left(3 \mathrm{Bel}_{j}+\mathrm{Pl}_{j}\right) / 2\right)} .
$$

Step 3: belief-plausible positive-ideal solution and belief-plausible negative-ideal solution

In the TOPSIS method, the evaluation criteria $C$ can be divided into two disjoint sets, i.e., the benefit criteria $P_{1}$ and the cost criteria $P_{2}$, where $P_{1} \subseteq C, P_{2} \subseteq C$, and $P_{1} \cap P_{2}=\phi$. According to BPIs of IFSs and keeping in view the principle of the TOPSIS method, belief- 
plausible positive-ideal solution (BPPIS) and beliefplausible negative-ideal solution (BPNIS) can be defined as follows:

$$
\begin{aligned}
& A^{+}=\left\{\left\langle C_{j},\left[\mathrm{Bel}_{j}^{+}, \mathrm{Pl}_{j}^{+}\right]\right\rangle: C_{j} \in C\right\}, \\
& A^{-}=\left\{\left\langle C_{j},\left[\mathrm{Bel}_{j}^{-}, \mathrm{Pl}_{j}^{-}\right]\right\rangle: C_{j} \in C\right\},
\end{aligned}
$$

where $\left[\mathrm{Bel}_{j}^{+}, \mathrm{Pl}_{j}^{+}\right]=[1,1]$ and $\left[\mathrm{Bel}_{j}^{-}, \mathrm{Pl}_{j}^{-}\right]=[0,0]$ if $j \in P_{1}$ and $\left[\mathrm{Bel}_{j}^{+}, \mathrm{Pl}_{j}^{+}\right]=[0,0]$ and $\left[\mathrm{Bel}_{j}^{-}, \mathrm{Pl}_{j}^{-}\right]=[1,1]$ if $j \in P_{2}$.

Step 4: calculation of similarity measures from BPPIS and BPNIS

We use equations (13), (19), (20), and (21) to obtain the following weighted similarities: $s_{w L}(\widetilde{S}, \widetilde{T})=1-d_{w \mathrm{BPH}}$ $\left(\mathrm{BPI}_{\tilde{\mathcal{S}}}, \mathrm{BPI} \tilde{T}\right), \quad s_{w \mathrm{Q}}\left(\mathrm{BPI}_{\tilde{S}}, \mathrm{BPI}_{\tilde{T}}\right)=\left(\left(1-d_{w \mathrm{BPH}}\left(\mathrm{BPI}_{\tilde{\mathcal{S}}}\right.\right.\right.$, $\left.\left.\left.\mathrm{BPI}_{\widetilde{T}}\right)\right) /\left(1+d_{w \mathrm{BPH}}\left(\mathrm{BPI}_{\widetilde{S}}, \mathrm{BPI}_{\widetilde{T}}\right)\right)\right)$, and $s_{w E}(\widetilde{S}, \widetilde{T})=$ $\left(\left(e^{-d_{w \mathrm{BPH}}\left(\mathrm{BPF}_{S} \mathrm{BP} T\right)}-e_{T}^{-1}\right) /\left(1-e^{-1}\right)\right)$. These similarities will assist us to construct similarity measures of each alternative $A_{i}$ from positive-ideal solution $A^{+}$and negative-ideal solution $A^{-}$, respectively, as

$$
\begin{aligned}
\widetilde{E}^{+}\left(A_{i}\right) & =s\left(A^{+}, A_{i}\right), \\
\widetilde{E}^{-}\left(A_{i}\right) & =s\left(A_{i}, A^{-}\right), \\
i & =1,2, \ldots, m .
\end{aligned}
$$

Step 5: calculation of relative closeness coefficient and ranking of alternatives

The relative closeness coefficient (RCC) $\widetilde{N}_{k}\left(A_{i}\right)$ of each alternative $A_{i}$ with respect to the belief and plausible ideal solution is obtained by the following expression:

$$
\widetilde{N}\left(A_{i}\right)=\frac{\widetilde{E}^{-}\left(A_{i}\right)}{\widetilde{E}^{-}\left(A_{i}\right)+\widetilde{E}^{+}\left(A_{i}\right)}, \quad i=1,2, \ldots, m .
$$

Finally, the alternatives are ordered according to the relative closeness degrees. The ranking order of all alternatives can be determined according to ascending order of the relative closeness degrees. The most preferred alternative is the one with the highest relative closeness degree.

Example 5. Assume that a customer wants to purchase a car. The following five car companies as alternatives $A=\left\{A_{1}, A_{2}, \ldots, A_{5}\right\}$ are taken into consideration. Before buying a car, the customer takes into account the following four criteria: (1) price $\left(C_{1}\right),(2)$ fuel economy and safety $\left(C_{2}\right),(3)$ remote keyless entry system (RKES) $\left(C_{3}\right)$, and (4) comfort and electronic stability. We notice that $C_{1}$ is cost criteria, and so $C_{1} \in P_{2}, C_{2}, C_{3}$, and $C_{4}$ are benefit criteria. Thus, $C_{2}, C_{3}$, and $C_{4} \in P_{1}$. The evaluation values of five possible alternatives $A=\left\{A_{1}, A_{2}, \ldots, A_{5}\right\}$ under the above four criteria can be denoted by the following IFSs:

$$
\begin{aligned}
& A_{1}=\left\{\left\langle C_{1},(0.5,0.2)\right\rangle,\left\langle C_{2},(0.3,0.1)\right\rangle,\left\langle C_{3},(0.4,0.5)\right\rangle,\left\langle C_{4},(0.6,0.2)\right\rangle\right\}, \\
& A_{2}=\left\{\left\langle C_{1},(0.5,0.4)\right\rangle,\left\langle C_{2},(0.1,0.6)\right\rangle,\left\langle C_{3},(0.3,0.2)\right\rangle,\left\langle C_{4},(0.5,0.1)\right\rangle\right\}, \\
& A_{3}=\left\{\left\langle C_{1},(0.7,0.2)\right\rangle,\left\langle C_{2},(0.5,0.3)\right\rangle,\left\langle C_{3},(0.1,0.6)\right\rangle,\left\langle C_{4},(0.3,0.2)\right\rangle\right\}, \\
& A_{4}=\left\{\left\langle C_{1},(0.3,0.5)\right\rangle,\left\langle C_{2},(0.6,0.3)\right\rangle,\left\langle C_{3},(0.4,0.1)\right\rangle,\left\langle C_{4},(0.6,0.0)\right\rangle\right\}, \\
& A_{5}=\left\{\left\langle C_{1},(0.2,0.3)\right\rangle,\left\langle C_{2},(0.9,0.0)\right\rangle,\left\langle C_{3},(0.5,0.3)\right\rangle,\left\langle C_{4},(0.6,0.1)\right\rangle\right\} .
\end{aligned}
$$

Step 1: the construction of corresponding BPDM is displayed in Table 2.

Step 2: the following weights of criteria are calculated by using equation (25) as follows:

$$
\begin{aligned}
& \widetilde{w}_{1}=0.3048, \\
& \widetilde{w}_{2}=0.2524, \\
& \widetilde{w}_{3}=0.2141, \\
& \widetilde{w}_{4}=0.2288 .
\end{aligned}
$$

Step 3: in this step, we calculate BPPIS and BPNIS as follows:

$$
\begin{aligned}
& A^{+}=\{[0.0,0.0],[1.0,1.0],[1.0,1.0],[1.0,1.0]\}, \\
& A^{-}=\{[1.0,1.0],[0.0,0.0],[0.0,0.0],[0.0,0.0]\} .
\end{aligned}
$$

Step 4: similarity measures from BPPIS and BPNIS are shown in Table 3.

Step 5: the relative closeness coefficients (RCCs) using equation (28) are shown in Table 4. According to the increasing order of RCCs, the values of five alternatives are ranked, and the alternative with the highest value is considered as the ideal one, as shown in Table 5.

From Table 5, it is seen that the preference ordering of the alternatives by using the proposed similarity measures of equations (19)-(21) for BPIs of IFSs are all the same with the same best alternative. That is, there is no conflict in the preference ordering of all the alternatives for BPIs of IFSs in 
TABLE 2: Belief-plausible decision matrix.

\begin{tabular}{lcccc}
\hline \multirow{2}{*}{ Alternatives } & \multicolumn{4}{c}{ Criteria evaluation } \\
& $C_{1}$ & $C_{2}$ & $C_{3}$ & $C_{4}$ \\
\hline$A_{1}$ & {$[0.5,0.8]$} & {$[0.3,0.9]$} & {$[0.4,0.5]$} & {$[0.6,0.8]$} \\
$A_{2}$ & {$[0.5,0.6]$} & {$[0.1,0.4]$} & {$[0.3,0.8]$} & {$[0.5,0.9]$} \\
$A_{3}$ & {$[0.7,0.8]$} & {$[0.5,0.7]$} & {$[0.1,0.4]$} & {$[0.3,0.8]$} \\
$A_{4}$ & {$[0.3,0.5]$} & {$[0.6,0.7]$} & {$[0.4,0.9]$} & {$[0.6,1.0]$} \\
$A_{5}$ & {$[0.2,0.7]$} & {$[0.9,1.0]$} & {$[0.5,0.7]$} & {$[0.6,0.9]$} \\
\hline
\end{tabular}

which the belief-plausible TOPSIS gets the right choice of the alternative $A_{3}$.

We further make a comparison analysis to demonstrate the effectiveness of the proposed belief-plausible TOPSIS. As we know, except the TOPSIS, there are other ways to be used for handling MCDM problems. We next consider another way to solve the MCDM problem for buying a car of Example 5. The construction is as follows:

Step 1: construction of belief-plausible decision matrix Based on the decision matrix $\widetilde{D}^{*}=\left(\widetilde{a}_{i j}\right)_{m \times n}=\left(\left\langle u_{i j}, v_{i j}\right\rangle\right)$ with its corresponding $\operatorname{BPDM} \widetilde{D}=\left[\tilde{b}_{i j}\right]_{m \times n}=\left[\mathrm{Bel}_{i j}, \mathrm{Pl}_{i j}\right]$ where $\mathrm{Bel}_{i j}=u_{i j}$ and $\mathrm{Pl}_{i j}=1-v_{i j}$, we specify the options $A=\left\{A_{1}, A_{2}, \ldots, A_{m}\right\}$ by the characteristic set $A_{i}=\left\{\left\langle C_{j},\left[\mathrm{Bel}_{i j}, \mathrm{Pl}_{i j}\right]\right\rangle: C_{j} \in C\right\}$.

Step 2: determination of the weights of criteria

In this step, we calculate criteria weights. The weights can be also obtained by the same way of equation (25) with $\widetilde{w}_{j}=\left(\left(\left(3 \mathrm{Bel}_{j}+\mathrm{Pl}_{j}\right) / 2\right) / \sum_{j=1}^{n}\left(\left(3 \mathrm{Bel}_{j}+\mathrm{Pl}_{j}\right) / 2\right)\right)$.

Step 3: construction of a belief ideal solution The belief ideal solution $A^{*}$ is generally constructed with

$A^{*}=\left\{\left\langle\left[\mathrm{Bel}_{1}^{*}, \mathrm{Pl}_{1}^{*}\right]\right\rangle,\left\langle\left[\mathrm{Bel}_{2}^{*}, \mathrm{Pl}_{2}^{*}\right]\right\rangle, \ldots,\left\langle\left[\mathrm{Bel}_{n}^{*}, \mathrm{Pl}_{n}^{*}\right]\right\rangle\right\}$,

where $\left\langle\left[\mathrm{Bel}_{i}^{*}, \mathrm{Pl}_{i}^{*}\right]\right\rangle=\left\langle\left[\max _{j} \mathrm{Bel}_{i j}^{*}, \min _{j} \mathrm{Pl}_{i j}^{*}\right]\right\rangle$.

Step 4: calculation of similarity measures

Equations (19)-(21) are used to calculate the similarity measures $s\left(A_{i}, A^{*}\right)$.

Step 5: ranking of alternatives

Rank the alternatives $A_{i}$ in accordance with the degrees of similarities (19)-(21) and select the best alternative with maximum $s\left(A_{i}, A^{*}\right)$.

We use the data of Example 5 to rank the alternatives and then compare the ranking with the belief-plausible TOPSIS method:

Step 1. The construction of corresponding BPDM is exactly the same as Table 2.

Step 2. The weights of criteria are calculated with
TABLE 3: Similarity measure between each alternative $A_{i}$ to BPNIS $A^{-}$and BPPIS $A^{+}$.

\begin{tabular}{ccccccccc}
\hline$s_{w L}$ & $\widetilde{E}^{-}\left(A_{i}\right)$ & $\widetilde{E}^{+}\left(A_{i}\right)$ & $s_{w Q}$ & $\widetilde{E}^{-}\left(A_{i}\right)$ & $\widetilde{E}^{+}\left(A_{i}\right)$ & $s_{w E}$ & $\widetilde{E}^{-}\left(A_{i}\right)$ & $\widetilde{E}^{+}\left(A_{i}\right)$ \\
\hline$A_{1}$ & 0.3304 & 0.3595 & $A_{1}$ & 0.1979 & 0.2191 & $A_{1}$ & 0.2279 & 0.2518 \\
$A_{2}$ & 0.3694 & 0.3257 & $A_{2}$ & 0.2265 & 0.1945 & $A_{2}$ & 0.2601 & 0.2241 \\
$A_{3}$ & 0.4632 & 0.2771 & $A_{3}$ & 0.3014 & 0.1607 & $A_{3}$ & 0.3429 & 0.1858 \\
$A_{4}$ & 0.1885 & 0.5267 & $A_{4}$ & 0.1041 & 0.3575 & $A_{4}$ & 0.1207 & 0.4035 \\
$A_{5}$ & 0.1480 & 0.5628 & $A_{5}$ & 0.0799 & 0.3916 & $A_{5}$ & 0.0940 & 0.4397
\end{tabular}

TABle 4: Relative closeness coefficients.

\begin{tabular}{llllll}
\hline$s_{w L}$ & $\tilde{N}\left(A_{i}\right)$ & $s_{w Q}$ & $\tilde{N}\left(A_{i}\right)$ & $s_{w E}$ & $\tilde{N}\left(A_{i}\right)$ \\
\hline$A_{1}$ & 0.4789 & $A_{1}$ & 0.4746 & $A_{1}$ & 0.4751 \\
$A_{2}$ & 0.5314 & $A_{2}$ & 0.5380 & $A_{2}$ & 0.5372 \\
$A_{3}$ & 0.6257 & $A_{3}$ & 0.6521 & $A_{3}$ & 0.6486 \\
$A_{4}$ & 0.2636 & $A_{4}$ & 0.2255 & $A_{4}$ & 0.2303 \\
$A_{5}$ & 0.2082 & $A_{5}$ & 0.1695 & $A_{5}$ & 0.1761 \\
\hline
\end{tabular}

TABle 5: Ranking order of alternatives for different similarity methods.

\begin{tabular}{lcc}
\hline Method & Ranking & Best alternative \\
\hline$s_{w L}$ & $A_{5} \prec A_{4} \prec A_{1} \prec A_{2} \prec A_{3}$ & $A_{3}$ \\
$s_{w Q}$ & $A_{5} \prec A_{4} \prec A_{1} \prec A_{2} \prec A_{3}$ & $A_{3}$ \\
$s_{w E}$ & $A_{5} \prec A_{4} \prec A_{1} \prec A_{2} \prec A_{3}$ & $A_{3}$ \\
\hline
\end{tabular}

$$
\begin{aligned}
& \widetilde{w}_{1}=0.3048, \\
& \widetilde{w}_{2}=0.2524, \\
& \widetilde{w}_{3}=0.2141, \\
& \widetilde{w}_{4}=0.2288 .
\end{aligned}
$$

Step 3. The belief ideal solution $A^{*}$ is constructed with $A^{*}=\{\langle[0.7,0.5]\rangle,\langle[0.9,0.4]\rangle,\langle[0.5,0.4]\rangle,\langle[0.6,0.8]\rangle\}$.

Step 4. Similarity measures from each alternative $A_{i}$ to the ideal alternative $A^{*}$ are shown in Table 6 .

The maximum similarity between alternatives $A_{i}$ to the ideal alternative $A^{*}$, as shown in Table 6 , is considered as the best alternative. Thus, according to the maximum similarity rule, Table 7 shows the ranking of each alternative $A_{i}$ in preferred order.

From Table 7, it is seen that the preference ordering of alternatives by using this way all shows the alternative $A_{1}$ as the best alternative. This method shows the conflict in ranking of alternatives. However, from Table 5, it is seen that the belief-plausible TOPSIS method actually ranks the alternatives according to our intuition, and there was no any conflict in ranking. 
TABLE 6: Similarity measures from each alternative $A_{i}$ to the ideal alternative.

\begin{tabular}{cccccc}
\hline & $s_{w L}$ & & $s_{w Q}$ & $s_{w E}$ \\
\hline$s_{w L}\left(A_{1}, A^{*}\right)$ & 0.9339 & $s_{w Q}\left(A_{1}, A^{*}\right)$ & 0.8760 & $s_{w E}\left(A_{1}, A^{*}\right)$ & 0.8988 \\
$s_{w L}\left(A_{2}, A^{*}\right)$ & 0.9072 & $s_{w Q}\left(A_{2}, A^{*}\right)$ & 0.8301 & $s_{w E}\left(A_{2}, A^{*}\right)$ & 0.8597 \\
$s_{w L}\left(A_{3}, A^{*}\right)$ & 0.9133 & $s_{w Q}\left(A_{3}, A^{*}\right)$ & 0.8404 & $s_{w E}\left(A_{3}, A^{*}\right)$ & 0.8686 \\
$s_{w L}\left(A_{4}, A^{*}\right)$ & 0.9124 & $s_{w Q}\left(A_{4}, A^{*}\right)$ & 0.8389 & $s_{w E}\left(A_{4}, A^{*}\right)$ & 0.8528 \\
$s_{w L}\left(A_{5}, A^{*}\right)$ & 0.9212 & $s_{w Q}\left(A_{5}, A^{*}\right)$ & 0.8220 & $s_{w E}\left(A_{5}, A^{*}\right)$ & 0.8220 \\
\hline
\end{tabular}

TABLE 7: Ranking order of alternatives for different similarity methods.

\begin{tabular}{lcc}
\hline Method & Ranking & Best alternative \\
\hline$s_{w L}$ & $A_{2} \prec A_{4} \prec A_{3} \prec A_{5} \prec A_{1}$ & $A_{1}$ \\
$s_{w Q}$ & $A_{5} \prec A_{2} \prec A_{4} \prec A_{3} \prec A_{1}$ & $A_{1}$ \\
$s_{w E}$ & $A_{5} \prec A_{4} \prec A_{1} \prec A_{2} \prec A_{3}$ & $A_{1}$ \\
\hline
\end{tabular}

\section{Conclusions}

Many attempts had been made in the literature about the improvement in information measures, but there is still much room to improve these measures in a better way and use them to find new applications and novel directions. Although there are some generalizations of DST to fuzzy sets in the literature, there is less generalization of DST to IFSs. In this paper, we first use memberships and nonmemberships for an element in an IFS to express the degrees of belief and plausibility for the element in the IFSs and then propose a simple and intuitive way to compute belief and plausibility measures on IFSs. This gives a type of generalization of DST to IFSs. Based on the proposed belief and plausibility measures on IFSs, we construct belief-plausibility intervals (BPIs) of IFSs and then define Hausdorff distance between BPIs. This construction makes it possible to establish similarity measures of IFSs in the context of DST. The proposed approach to belief and plausibility measures on IFSs in the framework of DST enables us to solve multicriteria decisionmaking by extending TOPSIS to the belief-plausible TOPSIS. Several examples are presented to demonstrate these suitability, reliability, and validity of the proposed methods. Based on computational results, it is seen that the proposed methods are reasonable and well-suited in the environment of IFSs in the content of DST.

\section{Data Availability}

All data are included in the manuscript.

\section{Conflicts of Interest}

The authors declare that they have no conflicts of interest.

\section{Acknowledgments}

This work was supported in part by the Ministry of Science and Technology, Taiwan, under Grant MOST 107-2118-M033-002-MY2.

\section{References}

[1] A. P. Dempster, "Upper and lower probabilities induced by a multivalued mapping," The Annals of Mathematical Statistics, vol. 38, no. 2, pp. 325-339, 1967.

[2] G. Shafer, A Mathematical Theory of Evidence, Princeton University Press, Princeton, NJ, USA, 1976.

[3] A. P. Dempster and W. F. Chiu, "Dempster-Shafer models for object recognition and classification," International Journal of Intelligent Systems, vol. 21, no. 3, pp. 283-297, 2006.

[4] L. Karanikola and I. Karali, "Towards a Dempster-Shafer fuzzy description logic-handling imprecision in the semantic web," IEEE Transactions on Fuzzy Systems, vol. 26, no. 5, pp. 3016-3026, 2018.

[5] L. A. Zadeh, "Fuzzy sets," Information and Control, vol. 8, no. 3, pp. 338-353, 1965.

[6] K. T. Atanassov, "Intuitionistic fuzzy sets," Fuzzy Sets and Systems, vol. 20, no. 1, pp. 87-96, 1986.

[7] K. Atanassov, Intuitionistic Fuzzy Sets, Theory and Applications, Springer Pyhsica-Verlag, New York, NY, USA, 1999.

[8] M. I. Ali, F. Feng, T. Mahmood, I. Mahmood, and H. Faizan, "A graphical method for ranking Atanassov's intuitionistic fuzzy values using the uncertainty index and entropy," International Journal of Intelligent Systems, vol. 34, no. 10, pp. 2692-2712, 2019.

[9] T. Mahmood, P. Liu, J. Ye, and Q. Khan, "Several hybrid aggregation operators for triangular intuitionistic fuzzy set and their application in multi-criteria decision making," Granular Computing, vol. 3, no. 2, pp. 153-168, 2018.

[10] D. Bijan, N. Jan, T. Mahmood, and K. Ullah, "Intuitionistic fuzzy graphs of nth type with applications," Journal of Intelligent \& Fuzzy Systems, vol. 36, no. 4, pp. 3923-3932, 2019.

[11] L. A. Zadeh, "Fuzzy sets and information granularity," in Advances in Fuzzy Sets Theory and Application, M. M. Gupta, R. K. Ragade, and R. R. Yager, Eds., pp. 3-18, North-Holland, Amsterdam, Netherlands, 1979.

[12] R. R. Yager, "Generalized probabilities of fuzzy events from fuzzy belief structures," Information Sciences, vol. 28, no. 1, pp. 45-62, 1982.

[13] J. Yen, "Generalizing the Dempster-Schafer theory to fuzzy sets," IEEE Transactions on Systems, Man, and Cybernetics, vol. 20, no. 3, pp. 559-570, 1990.

[14] C. Lucas and B. N. Araabi, "Generalization of the DempsterShafer theory: a fuzzy-valued measure," IEEE Transactions on Fuzzy Systems, vol. 7, no. 3, pp. 255-270, 1999.

[15] C.-M. Hwang and M.-S. Yang, "Generalization of belief and plausibility functions to fuzzy sets based on the Sugeno integral," International Journal of Intelligent Systems, vol. 22, no. 11, pp. 1215-1228, 2007.

[16] C.-M. Hwang and M.-S. Yang, "Belief and plausibility functions on Intuitionistic fuzzy sets," International Journal of Intelligent Systems, vol. 31, no. 6, pp. 556-568, 2016.

[17] L. Dymova and P. Sevastjanov, "An interpretation of intuitionistic fuzzy sets in terms of evidence theory: decision making aspect," Knowledge-Based Systems, vol. 23, no. 8, pp. 772-782, 2010.

[18] L. Dymova and P. Sevastjanov, "The operations on intuitionistic fuzzy values in the framework of Dempster-Shafer theory," Knowledge-Based Systems, vol. 35, pp. 132-143, 2012.

[19] C.-M. Hwang, M.-S. Yang, W.-L. Hung, and M.-G. Lee, “A similarity measure of intuitionistic fuzzy sets based on the Sugeno integral with its application to pattern recognition," Information Sciences, vol. 189, pp. 93-109, 2012. 
[20] C.-M. Hwang, M.-S. Yang, and W.-L. Hung, "New similarity measures of intuitionistic fuzzy sets based on the Jaccard index with its application to clustering," International Journal of Intelligent Systems, vol. 33, no. 8, pp. 1672-1688, 2018.

[21] R. Joshi, S. Kumar, D. Gupta, and H. Kaur, "A Jensen- $\alpha$-norm dissimilarity measure for intuitionistic fuzzy sets and its applications in multiple attribute decision making," International Journal of Fuzzy Systems, vol. 20, no. 4, pp. 11881202, 2018.

[22] M.-S. Yang and Z. Hussain, "Distance and similarity measures of hesitant fuzzy sets based on Hausdorff metric with applications to multi-criteria decision making and clustering," Soft Computing, vol. 23, no. 14, pp. 5835-5848, 2019.

[23] A. I. Ban, Intuitionistic Fuzzy Measures: Theory and Applications, Nova Science, New York, NY, USA, 2006.

[24] S. Salicone, "Measurement uncertainty: an approach via the mathematical theory of evidence," Springer Series in Reliability Engineering, Springer-Verlag, New York, NY, USA, 2006.

[25] S. Salicone, "The theory of evidence: a new promising approach to the evaluation and expression of measurement uncertainty," IEEE Instrumentation \& Measurement Magazine, vol. 16, no. 1, pp. 18-23, 2013.

[26] S. B. Nalder Jr., Hyperspaces of Sets, Marcel Dekker, New York, NY, USA, 1978.

[27] D. P. Huttenlocher, G. A. Klanderman, and W. J. Rucklidge, "Comparing images using the Hausdorff distance," IEEE Transactions on Pattern Analysis and Machine Intelligence, vol. 15, no. 9, pp. 850-863, 1993.

[28] L. A. Zadeh, "Similarity relations and fuzzy orderings," Information Sciences, vol. 3, no. 2, pp. 177-200, 1971.

[29] N. R. Pal and S. K. Pal, "Some properties of the exponential entropy," Information Sciences, vol. 66, no. 1-2, pp. 119-137, 1992.

[30] M. Lin, C. Huang, and Z. Xu, "TOPSIS method based on correlation coefficient and entropy measure for linguistic Pythagorean fuzzy sets and its application to multiple attribute decision making," Complexity, vol. 2019, Article ID 6967390, 16 pages, 2019.

[31] M. S. Yang and K. L. Wu, "A similarity-based robust clustering method," IEEE Transactions on Pattern Analysis and Machine Intelligence, vol. 26, pp. 434-448, 2004.

[32] P. L. Yu, Multiple-Criteria Decision Making: Concepts, Techniques, and Extensions, Plenum Press, New York, NY, USA, 1985.

[33] M. S. Yang and Z. Hussian, "Fuzzy entropy for Pythagorean fuzzy sets with application to multicriterion decision making," Complexity, vol. 2018, Article ID 2832839, 14 pages, 2018. 